\title{
Pathways of Global Cultural Diffusion: Mass Media and People's Moral Declarations about Men's Violence against Women
}

By: Jeffrey Swindle, Harvard College Fellow, Department of Sociology, Harvard University jswindle@g.harvard.edu

December 28, 2022

Abstract: Current theories of global cultural diffusion outline abstract mechanisms through which cultural scripts spread across the world. To reveal how scripts reach individuals, it is necessary to identify the specific pathways of diffusion. I examine the case of how scripts about gender relations and violence are diffused through mass media to people in Malawi. Using a mixed methods approach, I find that international development organizations work with Malawian journalists to produce an array of content denouncing the practice of men abusing women. However, entertainment media companies disseminate content portraying patriarchal gender stereotypes. I show that mass media content critical of men's violence of women is positively associated with people's stated rejection of this practice, while individuals' exposure to content mixed with patriarchal scripts is not. Notably, a one standard deviation increase in the number of newspaper articles critically covering men's abuse toward women in the 30 days leading up to when a survey respondent is personally interviewed is associated with a 3.2 (women) or 2.1 (men) percentage point increase in their probability of stating that they condemn such violence. Broadly, the results outline a multifaceted portrait of global cultural diffusion, with liberal and patriarchal scripts simultaneously reaching individual people.

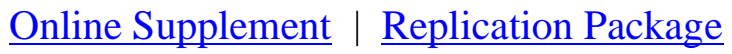

Acknowledgements: I thank Deirdre Bloome, Margaret Frye, Arland Thornton, and Kiyoteru Tsutsui for their detailed comments on earlier versions of this paper. I am grateful for advice I received from members of the Inequality, Demography, and Family working group at the University of Michigan, as well as Adam Ashforth, Cheyney Dobson, Emma Kaliya, Japhet Mchakulu, Limbani Moya, Henry Mphande, Florence Nkhoma, Limbani Phiri, Louisa Roberts, Sarah Seelye, Ann Swidler, Susan Watkins, Brady West, and many others.

Funding: I received research support from NIA training grant T32AG000221 and NICHD training grant T32HD007339 awarded to the Population Studies Center at the University of Michigan, as well as a NICHD training grant (T32HD007081) awarded to the Population Research Center at the University of Texas at Austin. I also gratefully acknowledge use of the services and facilities of the Population Studies Center at the University of Michigan and the Population Research Center at the University of Texas at Austin funded by NICHD center grants P2CHD041028. I further received research grants from the Department of Afroamerican and African Studies, Department of Sociology, African Studies Center, International Institute, Population Studies Center, and School of Natural Resources and Environment at the University of Michigan. The research content is solely my responsibility and does not necessarily represent the official views of any funders. 


\section{Pathways of Global Cultural Diffusion:}

\section{Mass Media and People's Moral Declarations about Men's \\ Violence against Women}

\section{INTRODUCTION}

International development organizations like the United Nations, World Bank, Gates Foundation, and CARE International circulate a battery of liberal cultural scripts under the umbrella of "development." Such scripts posit the importance of economic growth for advancing social tolerance, the benefits of small families, and the notion of inalienable human rights (Meyer et al. 1997; Thornton 2005). Likewise, national governments, domestic non-governmental organizations (NGOs), and local activists take up and share these liberal scripts, as well as creatively proposing new additions and modifications (McDonnell 2016; Tamale 2014; Tsutsui 2018). Collectively, these globally-oriented and locally-grounded networks of actors can shape countries' policies and, in some cases, their practices (Cole and Ramirez 2013; Hafner-Burton and Tsutsui 2005).

It has long been recognized that the same institutional forces that encourage policy convergence across national governments likely extend their reach to individual people (Frank and Meyer 2002). Large majorities of citizens across diverse societies increasingly make moral declarations during survey interviews that align with liberal scripts (Ron et al. 2017; Thornton et al. 2012). As such, there has been a gradual expansion of what Thornton et al. (2015) call “developmental idealism," which is an awareness or ascription to liberal cultural scripts about societal development and human rights at the level of individual people around the world. 
Regardless of whether respondents' moral declarations that align with liberal scripts are predictive of their subsequent behavior (Johnson-Hanks et al. 2011), reflective of their desired personal identities (Frye 2012), or shaped by what they think interviewers want to hear (Angotti and Kaler 2013), such personal statements are important for cultural analysis because they are indicative of a public-to-personal diffusion process: they show whether liberal scripts are reaching people across the world and whether people consider these scripts to be powerful and important (Behrman and Frye 2021:23-24; Meyer 1986:216; Pierotti 2013:261-262; see also Lizardo 2017:103-104).

What remains unsettled in research on global cultural diffusion are the pathways through which cultural scripts reach individuals. Researchers rely on proxy measures for exposure to liberal scripts, like people's level of education or mass media use, or the number of international NGOs present in their country (for a review, see Hadler 2017). However, several scholars lament that they cannot measure variation in the prevalence of liberal scripts within the theorized sources of diffusion (e.g., Boyle et al. 2002:26; Hendi 2017:235; Pierotti 2013:261). A parallel limitation is a lack of investigation into people's coinciding exposure to alternative scripts promoted by other globalizing organizations. In particular, illiberal social movements and many national governments now present a formidable global network of antagonism toward democracy, higher education, gender equality, the rights of lesbian, gay, bisexual, trans, and queer (LGBTQ) persons, and liberalism in general (Lerch et al. 2021; Velasco forthcoming). While strands of illiberalism vary (Bonikowski 2017), they generally invoke a desire for an imagined past, of the way things used to be, especially with respect to patriarchal power, religiosity, and racism (Boyle et al. 2017; Goetz 2020). Institutional explanations of global 
cultural diffusion, therefore, must be broadened to consider liberal, illiberal, and other cultural scripts (Wimmer 2021:1419-1420).

I address these twin challenges through a mixed methods analysis of the relationship between mass media and people's moral declarations about men's violence against women in Malawi between 2000 and 2016. International development organizations, national governments, NGOs, and many activists use mass media campaigns to widely declare that gender violence is a violation of human rights (Merry 2006; Montoya 2013). At the same time, entertainment media companies create and globally distribute a flood of content that is laden with patriarchal scripts and stereotypes about gender relations (Bleakley et al. 2012; Flynn et al. 2016). Accordingly, two questions arise: what cultural scripts about gender relations and violence flow through mass media to people in Malawi? How does individuals' exposure to these scripts, as contained in mass media, inform their moral declarations about men's violence against women? My focus in this article, in contrast, is on the diffusion of cultural scripts to individual people as manifested in their moral declarations. While acts of gender violence are inherently of interest, they are notoriously difficult to measure (Ellsberg et al. 2001). Moreover, meaningful long-term changes in violent behavior are unlikely without shifts in gender norms and moral declarations, especially when institutional authorities often dismiss survivors' appeals for assistance.

Malawi is of particular interest because international development organizations and domestic activists, along with foreign entertainment media companies, heavily influence the available mass media programming (Englund 2011; Gray 2011; Harris 2017). Moreover, in Malawi one-way forms of communication programming - like newspaper, radio, television, and movies - overwhelmingly represent the types of media people consume, unlike in other societies where interactive forms of social media are more common (NSO and ICF 2017). In addition, 
between 2000 and 2016 the proportion of Malawians that self-reported being morally opposed to men's abuse of women rose substantially from 65 to 84 percent of women and from 75 to 87 percent of men, which are among the highest rates across African countries (ICF 2020). ${ }^{1}$

I begin my analysis by gathering and synthesizing information about the content of the mass media available to Malawians. To do so, I draw upon official reports from the national government and other organizations, domestic newspaper articles, and disparate literature by Malawian scholars. Using archival sources, I further collect and analyze a new dataset of all weekday newspaper articles in Malawi that discussed interpersonal violence. This information shows that Malawian NGOs and activists work with international development organizations to directly facilitate the production of mass media content disseminating liberal scripts critical of gender violence. They establish personal relationships with journalists and pay them for producing such content. Conversely, entertainment media companies spread content across Malawi that portray men as aggressive and women as submissive, thereby complicating the dominance of liberal messaging across different types of mass media.

I next use five cross-sectional national surveys_- which I link with the newspaper data I collected - to conduct a series of logistic regression models. cPeople's probability of stating that they reject men's violence against women is positively associated with mass media content featuring scripts denouncing such abuse, whereas their exposure to mass media content that is comparatively laden with patriarchal gender stereotypes is not. These tests are associational, yet estimates from models testing the effects of changes in the number of newspaper articles denouncing men's violence against women that are published in the days prior to survey respondents' personal interview dates are suggestive of a causal relationship. 
Combined, my analyses indicate that cultural scripts flow not only to national governments but also to individual people. Scripts come from multiple transnational sources, most notably immensely powerful international development organizations and their domestic partners but also influential entertainment media companies. These actors circulate liberal and patriarchal scripts through the same general sources of diffusion, in this case mass media. Tracing the specific pathways of global cultural diffusion clarifies how scripts reach individuals and demonstrates that multiple, seemingly contradictory scripts can simultaneously inform people's moral declarations.

\section{THE DIFFUSION OF CULTURAL SCRIPTS ABOUT GENDER VIOLENCE IN MASS}

\section{MEDIA}

The Rising Global Condemnation of Gender Violence

Cultural scripts about development and human rights are widely diffused worldwide (Meyer et al. 1997). Many actors are involved in this process: national governments, domestic activists and NGOs, and, notably, international development organizations. They construct and share liberal scripts with one another and then circulate them through such a wide variety of mediums that they can overwhelm societies and their citizens, leading to massive cultural and institutional change (Jepperson and Meyer 2011). Nevertheless, a more precise understanding of global cultural diffusion is possible — and necessary — through detailed measurement of the communication networks through which specific scripts travel across particular social environments (Velasco forthcoming; Wimmer 2021; Winkler 2021). Scholars analyzing the diffusion of liberal scripts at the individual-level are especially quick to recognize the importance of clarifying the pathways of diffusion, as existing proxy measures of script exposure are 
theoretical and their content is not directly measured (Charles 2020:112; Givens and Jorgenson 2013:421; Hadler 2017:37-44; Pierotti 2013:241-242). Several studies do show the proliferation of liberal scripts across textbooks and educational curricula (e.g., Russell et al. 2018), but until very recently studies on illiberal scripts are largely missing and research on the content disseminated via other domains of diffusion is limited (e.g., Cupać and Ebetürk 2020).

Of the many liberal scripts that international development organizations and other powerful organizations circulate, I focus on scripts that denounce men's violence against women, which for parsimony I refer to as anti-violence scripts. Many international development organizations, national governments, academic and policy experts, and political activists champion anti-violence scripts (Htun and Weldon 2012; Keck and Sikkink 1998, chapter 5; Merry 2006). The United Nations' 1993 Declaration on the Elimination of Violence against Women codified anti-violence scripts, stating, "violence against women is an obstacle to the achievement of equality, development and peace" (UN 1993:1). This sentiment was further expanded in the 1995 Fourth World Conference on Women in Beijing: "violence against women both violates and impairs or nullifies the enjoyment by women of human rights and fundamental freedoms" (UN 1995:92). Public databases indicate that, as of 2020, 155 countries have national legislation specifically outlawing domestic violence (World Bank 2021) and 191 have ratified the Convention on the Elimination of All Forms of Discrimination against Women (UN 2021).

Changes in moral statements about men's abusive behavior have also come through in public opinion data. Using national estimates obtained from the cross-national Demographic and Health Surveys, I show in Figure 1 that, on average, people's self-reported moral objection to men's abuse of women when asked on surveys has substantially increased over time in most nations sampled across Africa, Asia, Latin America, and the Middle East, including in Malawi, 
the focus on my analysis (ICF 2020; see also Cools and Kotsadam 2017; Kurzman et al. 2019; Pierotti 2013). Since 2000, stated rejection of men's physical abuse of their wives increased across 41 of 45 countries among women and 28 of 33 countries among men (see Section 1 of the Online Supplement). In general, temporal shifts in moral declarations tend to be slow and tied to cohort replacement (Kiley and Vaisey 2020). The temporal shift in stated rejection of men's abuse of women does not fit this explanation, though, because in the vast majority of countries an individual's age is positively — not negatively — associated with their probability of morally objecting to abuse, and decomposition analyses come to a similar conclusion (Alesina et al. 2021; Pierotti 2013). There are undoubtedly many factors involved in this global temporal shift, including but not limited to the spread of anti-violence scripts worldwide. ${ }^{2}$

[Figure 1]

\section{The Role of Mass Media}

The international networks of actors promoting liberal scripts work together to circulate anti-violence scripts through a variety of means. Scholars have documented discussion of gender violence in textbooks used in public education across the world (Russell et al. 2018) and shown how international development organizations collaborate with activists in specific settings to promote anti-violence scripts (Levitt and Merry 2011). They also argue that liberal scripts are prominent in mass media, particularly in targeted mass media programs designed to diffuse such ideas. This theorizing is consistent with several experimental studies that observe positive treatments effects of anti-violence media programs on recipients' stated rejection of the notion that men are justified in abusing women, including evidence from specific areas of Mexico (Arias 2019), Nigeria (Banerjee et al. 2019), and Uganda (Abramsky et al. 2014), but such outcomes are not universal across programs (Green 2021). 
In analyses using national surveys, researchers often use measures of people's mass media consumption broadly-speaking. For example, Pierotti (2013) found a significant positive association between women's at least weekly mass media use (coded as either newspaper, radio, or television use) and their stated rejection of men's violence against women in just over half of the 26 countries she analyzed and a significant negative association only in India. These crosssectional results provide fair but not outright support for the argument that anti-violence scripts likely flow through mass media. A series of more recent cross-sectional studies that distinguished between a person's types of mass media use — newspaper, radio, and televisioninterestingly found a variety of positive, negative, and null relationships with their expressed objection of men's abuse of women (e.g., Forsyth and Ward 2021; Jesmin and Amin 2017; Wang 2018; see also La Ferrara 2016:801-811). Winkler (2021) similarly observed varied associations between people's stated feelings about having a LGBTQ neighbor and their different forms of mass media consumption in a study of African countries. These findings, paired with Pierotti's somewhat non-absolute conclusions, underscore that liberal scripts may not be the only forms of cultural messaging in mass media programming.

To that point, powerful global entertainment media companies based in the United States, China, Nigeria, India, and various European nations all produce programming filled with patriarchal gender stereotypes about masculinity and femininity, as demonstrated by large-scale content analyses of the popular movies, television shows, and music they circulate (Flynn et al. 2016; Ghaznavi et al. 2017; Liebler et al. 2015). Male characters are especially common and they are more likely to be portrayed as aggressive and violent, whereas women are often depicted as submissive. Meta-analyses indicate that people's exposure to content featuring such stereotypical depictions of women and men is associated with expressing support for men's abuse of women 
(Rhodes et al. 2018; Ward 2016; Ward and Grower 2020). Thus, understanding the nature of mass media content, especially as it relates to gender violence, is vital. To be sure, the content entertainment media companies share often promotes models of femininity that are not patriarchal in other respects, such as soap operas and movies featuring women pursuing higher education, working outside the home, and having few children (e.g., Riley 2022).

Additionally, the influence of mass media should not be restricted to individual's personal consumption. Salient issues in mass media can orient what people discuss in public conversation (Katz and Lazarsfeld 1955; Zaller 1992). Friends and family may bring up an issue that they heard about on the radio, work colleagues might discuss a newspaper article one of them read, or a religious leader might orient their weekly discourse in response to recent mass media coverage (Jeong and Bae 2018; Solovei and van den Putte 2020). The public delivery of mass media, therefore, "helps individuals to form an understanding of their shared beliefs" (Arias 2019:565). Furthermore, the circulation of liberal scripts in mass media content may occur alongside other efforts: rallies and awareness campaigns, giving away free clothing and posters with related slogans, and working with religious and community leaders to ensure they share the cultural scripts in question (see McDonnell 2010; Trinitapoli and Weinreb 2012). As such, positive associations between the introduction of new forms of mass media and individuals' stated rejection of men's violence against women (e.g., Jensen and Oster 2009) may not be attributable solely to people's direct exposure to new ideas within their personal mass media consumption, but rather to the development of new "social norms via coordination" (Arias 2019:562). Exclusive focus on individual-level treatments misses how mass media content can both shape the social environment and reflect broader efforts to do so, which in turn can influence individuals (Thornton 2005:227). 
Moreover, time-varying data on mass media content can be temporally matched to individual-level survey data. A few scholars recently have done so, in particular Huang et al. (2021), who show that more than half the variance in American public opinion about China is explained by the sentiment about China expressed in The New York Times newspaper the previous year. Yet, researchers can be even more detailed by linking the specific interview dates of individual survey respondents to the mass media content published just prior (Brosius et al. 2019; de Vreese et al. 2017). This technique can be applied to the relationship between the prevalence of cultural scripts about men's abuse of women in mass media in the days preceding a person's unique survey interview date and their moral declarations about such violence.

\section{THE EMPIRICAL CASE OF MALAWI}

\section{Gender Relations}

Malawi features a layered cultural history from which a person might draw upon when declaring their views about men's violence against women. While land ownership is generally passed down through the mother's line (except in the northern region), women's power and autonomy has been constrained by a variety of forces that have promoted patriarchal family structures and ideologies, including but not limited to European colonizers, Christian missionaries, Swahili and Arab traders that introduced Islam, and Malawi's first President post-

independence - Hastings Banda, who led the country until the 1990s under his patriarchal vision of "our African way of life" (Kambalame et al. 2008; see also Kudo 2017; Peters 1997; Sicard 2000). More recently, the government passed the Protection against Domestic Violence Act in 2006 after much pressure from domestic activists and international development organizations (Kanyongolo and White 2017). The law provides substantive legal remedies and social services 
to victims. The national government now presents itself as firmly committed to challenging what it describes as, "strong attitudes about women being subservient to men" that are “institutionalized” (Malawi MGCDSW 2014:36).

Thus, people in Malawi today can draw upon either anti-violence or patriarchal scripts about gender relations. This fluidity matches Malawian social scientists and foreign ethnographers' observations that Malawians use two distinct Chichewa terms—nkhanza and kulangiza - when discussing interpersonal violence (Chichewa is the most common language and very widely spoken). Nkhanza describes the unjustified actions of a physically violent husband but also more broadly, such as a parent that neglects to pay their children's school fees as referenced in one newspaper article titled "“Abuse' of School Children?” (The Nation, 2012-1210; see also Johnson 2018:18-19; Saur et al. 2005). Kulangiza, in contrast, means advising, counseling, and disciplining. It is usually verbal, but sometimes physical violence is considered morally imperative (Chepuka et al. 2014; Nthala 2013:65).

\section{Mass Media Sources, Public Consumption, and Content Styles}

Mass media is a primary medium for circulating public cultural scripts in Malawi, including scripts about gender relations. Originally, the government-owned Malawi Broadcasting Corporation radio and television stations were the only media sources in Malawi; they aired only informational content and government propaganda and some music and sports (Harris 2017:2831; Lwanda and Kanjo 2013:32; c.f., Kamwendo 2008:276; Mitchell 2002:6). When Malawi transitioned to multiparty democracy and permitted freedom in the late 1990s, the Malawi Broadcasting Corporation became a formally independent, but tax-funded, public service media outlet, and by 2014 there were 34 regional or national radio stations and ten domestic or satellite television channels (NSO 2015:56-60, 70-73). There have been only two major daily newspapers 
in Malawi, The Daily Times and The Nation. However, one weekly tabloid, The Weekend Times, was quite popular while in circulation between 2009 and early 2014 (Nyasa Times 2014-01-31).

As shown in Figure 2, data from the nationally-representative Demographic and Health Surveys in Malawi indicate that radio is the most consumed type of mass media in Malawi between 2000 and 2016, followed by "television" (which most people in Malawi define as any visual content displayed on a television device, including movies), and then newspapers. Notably, there are declines since 2004 or 2010 in each type of mass media use. One possible contributing factor is a shaky economy: Malawians experienced a 31 percent decline in gross domestic product per person between 2010 and 2016, reaching a daily average of only $\$ 0.87$ (current USD) (World Bank 2022). Decreases in radio and television use may also be partly due to an increase in electrical blackouts, which are estimated to have increased eight-fold between 2009 and 2014 (World Bank 2019; see also NSO 2014; Taulo et al. 2015). It is possible that some are replacing their newspaper, radio, and television use with the internet, but even in 201516 less than 1.4 percent of women and 4.8 percent of men in Malawi said they used the internet at least weekly (NSO and ICF 2017:41-42), and such use was predominantly on mobile phones with limited online capabilities (NSO 2015:27-28).

[Figure 2]

Whereas radio is affordable, consistent with oral history practices, and generally broadcast in the widely-spoken Chichewa dialect and other common regional languages, newspapers are almost exclusively in English, a major limitation given that only 35 percent of men and 26 percent of women (ages 15-49) claimed English literacy during the 2008 census (MPC 2019). ${ }^{3}$ The few domestic television stations air a mixture of content in Chichewa and English, the half-dozen satellite stations accessible through the South African company 
MultiChoice show almost exclusively foreign television shows and movies in English (NSO 2015:72). ${ }^{4}$ Small video parlors set up near market centers show and sell digital copies of foreign movies, the content of which is primarily English or Mandarin with some movies in Hindi, Yoruba, and other languages (Geldof 2011; Gray 2011; UNESCO 2021:156-158). The video parlors expanded over time, but were prevalent in market centers nation-wide by the time Gray $(2011 ; 2014)$ conducted ethnographic work on them in 2008 and 2010. Foreign languages in television and movie content do not seem to deter people, rather, equipment cost and accessibility can (Gray 2014). In the later years of my analysis some entrepreneurs began producing personally dubbing foreign movies into Chichewa to great fanfare (Li 2022; TechZim 2013-12-30).

Beyond personal consumption, however, people in Malawi often discuss mass media content with others at the market, water hole, or bus station, or during community and religious meetings, as shown in ethnographic research (Kaler et al. 2015; Swidler and Watkins 2015; see also MHRRC 2013:41-44). For example, one Malawian ethnographer studying public discussions about HIV/AIDS observed a community leader state, "the message of HIV and AIDS is spread through many ways, like through the radio, in the prayer houses, at the market with friends, in the newspapers, at schools and many more places that a day cannot pass without hearing the message of HIV and AIDS” (Malawi Journals Project, 2011-12-17, Patuma_111202). ${ }^{5}$ Many people are likely similarly exposed to liberal and patriarchal scripts about gender relations present in mass media content in an indirect manner through others.

As outlined by Englund $(2011: 25-31,40)$, the basic theme in Malawian mass media over the years has been "developmentalism," which is the coverage of a range of topics posited to contribute to societal development, such as education, human rights, HIV/AIDS prevention, and 
gender equality (see also Angotti et al. 2014; Harris 2017:133-137). A recent cross-national study finds that journalists in Malawi see "supporting national development" as one of their primary goals (Kalyango et al. 2017).

There is nonetheless ample mass media content available to Malawians that is focused on entertainment rather than human rights messaging. This includes popular songs on the radio and music videos on television, scandals of infidelity and corruption among political leaders in The Weekend Times tabloid, sports coverage and celebrity gossip across all types of mass media, and especially foreign movies (Geston 2006:41-47, 76-83; Gray 2014; Li 2022; Mchakulu 2018). At a minimum, such content perpetuates gender stereotypes while diversifying the range of cultural material Malawians can consume and discuss with others beyond the liberal messaging pushed by international development organizations and their domestic partners.

\section{Research Aims}

To grasp the relationship between mass media content and persons' moral declarations about men's violence against women, it is imperative to first understand the nature of the mass media content available in Malawi, including the pathways through which anti-violence scripts and patriarchal scripts are uniquely disseminated. Once the diffusion pathways are identified, measures of different types of mass media can be interpreted more accurately. Given the power NGOs, activists, and international development organizations in Malawi, I anticipate that the dissemination of anti-violence scripts in mass media content is positively associated with stated rejection of men's violence against women. Entertainment media companies also wield significant cultural power, so I also expect that exposure to mass media content that tends to feature patriarchal gender stereotypes is negatively associated with stated rejection. 
To this end, I conduct a sequential mixed methods analysis (Small 2011:67-68). I begin by gathering and synthesizing evidence respecting the nature of mass media content in Malawi. In doing so, I trace the pathways through which different styles of content are diffused. I then use logistic regression analysis to assess the associations between Malawians' exposure to different forms of mass media content and their moral declarations about men's abuse of women. By examining these relationships separately for women and men, I ascertain whether anti-violence scripts and patriarchal scripts inform their moral declarations differently given their distinct social positions.

\section{DATA AND METHODS}

\section{Mass Media Assessment}

To collect information on mass media content, production, and circulation in Malawi, I visited the offices of the Malawian Broadcasting Corporation, the two main newspapers in Malawi, and the national archives in Zomba. I further went to the national offices of several branches of the national government, domestic NGOs, and international development organizations that were involved in gender violence campaigns in Malawi. As I met informally and had conversations with leaders at these institutions, they shared with me an array of official reports and newspaper articles. I combined this information with qualitative and quantitative evidence from Malawian scholars that has often been overlooked along with work by foreign ethnographers and other experts that discuss the history, production, and content of mass media in Malawi. In Section 2 of the Online Supplement, I list the official reports and newspaper articles that I cite (though not all those which I consulted), and the leaders with whom I met. 
With the help of research assistants Florence Nkhoma and Henry Mphande, I further created a new dataset of all newspaper articles that discussed interpersonal violence that were published in the Monday through Friday editions of Malawi daily newspapers The Daily Times and The Nation between January 1, 2000 and February 14, 2016 (the interview date of the final respondent in the last survey I use). Despite being the most long-standing and popular daily newspapers in Malawi, digital formats of their historical archives were limited so we located hard copies at several archives across the country. We visited the newspapers' official archives in Blantyre, two libraries in Lilongwe located at the Malawi Government's Human Rights Commission and the Malawi Human Rights Resource Centre, and one library in Zomba at the Center for Social Research at the University of Malawi. This was necessary to ensure full coverage of the two newspapers, as each archive or library was missing records due to water damage or staff transition.

We carefully looked through all of the pages of these newspapers during the time period, reading all article titles and then the full text of all articles that had titles related to violence, threats, gender relations, or sex. In total, we identified 2,754 newspaper articles that documented or abstractly discussed interpersonal violence, which we defined as a person forcefully undertaking any harmful or undesired action against another person. We took pictures of these articles and organized them in a database. I then trained thirteen exceptional undergraduate researchers to work with me to re-read all identified articles and code them for basic descriptors (article date, title, author, etcetera), the style of article (instance of interpersonal violence, coverage of NGO interventions addressing gender violence, opinion article, report about social movement activities, etcetera), and the demographic characteristics of all perpetrators and survivors listed as well as their relationship and the nature of the offenses described. ${ }^{6}$ 


\section{Regression Analysis}

To test the relationships between different types of mass media exposure and people's stated rejection of men's violence against women, I use five cross-sectional surveys conducted in Malawi: the 2000, 2004, 2010, and 2015-16 Demographic and Health Surveys (DHS) and the 2013-14 Multiple Indicator Cluster Survey (MICS). While distinct, the DHS and MICS use much of the same questionnaire and provide comparable estimates (Corsi et al. 2017; Hancioglu and Arnold 2013). The five surveys each featured a two-stage cluster design in which households were selected from enumeration areas that were selected from Malawi's 28 districts. ${ }^{7}$ All women between the ages of 15-49 from selected households were invited to participate in the women's samples. In one-third of the selected households, all men ages 15-54 (15-49 in the 2013-14 survey) were asked to be interviewed for the men's samples. ${ }^{8}$ Pooled together, the four surveys sampled 96,730 women and 27,848 men.

Dependent Variable. My dependent variable, stated rejection of men's violence against women, measures people's moral declarations that a husband is not justified in beating his wife from the following survey question: "Sometimes a husband is annoyed or angered by things that his wife does. In your opinion, is a husband justified in hitting or beating his wife in the following situations: (1) If she goes out without telling him? (2) If she neglects the children? (3) If she argues with him? (4) If she refuses to have sex with him? (5) If the food is not properly cooked?" Eighty-four percent of men and 78 percent of women say that a husband is not justified in beating his wife in any of the five proposed situations. The coefficient alpha from these five questions is 0.84 for women and 0.78 for men. Loadings from a single factor principalcomponent analysis range between $0.75-0.82$ for women and $0.71-0.75$ for men, indicating that 
the five questions tap into a single latent construct. Following others (e.g., Pierotti 2013), I use a binary variable identifying respondents that reject all five scenarios.

Independent Variables. There is ample temporal variation across the publication dates of newspaper articles about interpersonal violence. In addition, each survey was conducted over a period of five to six months. I draw upon this temporal variation to construct an individual-level measure of the number of newspaper articles with anti-violence scripts that were published in the 30 days prior to each survey respondent's particular interview date. For example, if a person were interviewed on April 20, 2014, then their assigned value would be the total number of articles with anti-violence scripts that were published between March 20 and April 19, 2014. Respondents interviewed on the same day share the same values, while those interviewed on the next day likely differ. In this count variable, I include articles about campaigns against men's abusive behavior toward women or articles that documented cases in which women were physically or sexually attacked by men.

To assess respondents' radio exposure to anti-violence scripts, I use survey questions asked in the 2000, 2004, and 2010 surveys stating, "In the last few months, have you listened to any of the following program series about family planning or health on the radio? Uchembere Wabwino (Safe Motherhood), Phukusi Lamoyo (Bag of Life), Umoyo M'Malawi (Health in Malawi), Dokotala Wapawailesi (Radio Doctor), or Chitukuko M'Malawi (Development in Malawi)? Though the survey question refers to these radio programs as being about family planning and health, all of the programs regularly share anti-violence scripts except the last one, which focuses on economic matters. I create a count measure of the number of the first four of these radio programs that respondents said they heard in the last few months. 
Additionally, I use three binary variables capturing respondents' at least weekly newspaper, radio, and television use, respectively. The assessment of mass media content guides my interpretation of these variables as mediums for exposure to either anti-violence scripts or patriarchal gender stereotypes or some combination of the two.

Modeling Strategy. I estimate several logistic regression models measuring the associations between Malawians' stated rejection of men's violence toward women and the independent variables related to mass media content and personal exposure. I condition these models using a series of variables influenced by both stated rejection and mass media exposure, which I draw from the literature: years of schooling, urban living, Christian religious identity, household wealth, heterosexual partnership history, matrilineal lineage, and age. Adjusting my models accordingly enables me to evaluate the association between the dependent variable and key independent variables without backdoor pathways influencing their relationship (Cunningham 2021; Elwert and Winship 2014). In the Online Supplement (Section 4), I describe the measurement of these variables and the theoretical motivations for their inclusion.

Consistent with the literature, I use a series of binary variables - one for each of the five surveys and one for each of Malawi's 28 districts—-because these factors may shape both individuals' mass media exposure and stated rejection of abuse (Cools and Kotsadam 2017; Kurzman et al. 2019). Survey variables help account for legal reforms over time as well as temporal changes in mass media accessibility. District variables are useful given unobserved differences that could geographically bias the estimates for mass media variables in my models, such as electricity blackouts or the number of informal video parlors (African Media Barometer 2012:27, 45; see also Grimm et al. 2015:1783). They also are important given other timeinvariant or historical factors that could influence Malawians moral declarations about men's 
abuse of women, namely the original settlement areas of the many societies present prior to European colonization as well as geographic variation in longstanding foreign influences from Christian missionaries, Islamic trade networks, and labor migration (Kudo 2017; Peters 1997; Sicard 2000).

To account for the complex survey design of the DHS, I calculate robust standard errors by clustering at the primary sampling unit and I assign the individual probability weights provided with each of the women's and men's surveys. Since comparing logistic regression coefficients within and across models is a well-established problem (Mood 2010), I convert all coefficient estimates to average marginal effects (AMEs), holding all other independent and covariates at their actual value for each observation (Long and Mustillo 2018). I interpret all AMEs as associations. Some mass media users likely seek out content consistent with their pretreatment views, so AMEs for personal newspaper, radio, and television use likely reflect a mixture of mass media effects and selection processes. However, selection processes do not cloud the association between a survey respondent's stated rejection of men's violence against women and the number of anti-violence newspaper articles published 30 days prior to their personal interview date.

I provide a replication package containing all necessary information and coding syntax to reproduce the quantitative aspects of my analyses, and I include copies of the official reports and newspaper articles that I cite. ${ }^{9}$

\section{THE FLOW OF ANTI-VIOLENCE AND PATRIARCHAL SCRIPTS ACROSS MASS MEDIA IN MALAWI}

Content that is Critical of Men's Violence against Women 
International development organizations and Malawian activists promote anti-violence scripts to Malawian media companies and journalists, who then produce specific newspaper articles, radio programs, and television shows for public consumption. Representatives from Malawi's offices of United Nations Women, United Nations Population Fund, and several foreign aid agencies, in partnership with some pan-African and Malawian NGOs, lead numerous “media trainings" for Malawian media personnel (Gender Links and Malawi Institute of Journalism 2001; Gender Links 2011; Morna 2010; Public Media Alliance 2012). ${ }^{10}$ At these multi-day workshops, they coach newspaper journalists, radio producers, and television writers about the importance of covering and denouncing gender violence while avoiding victimblaming in their content (The Daily Times 2004-11-29; The Nation 2016-11-27). Through these trainings, journalists establish valuable working relationships with contacts at domestic NGOs and international development agencies who gift them "brown bag" payments of \$10-15 USD for reporting positively on their initiatives (African Media Barometer 2012:58; Nyasa Times 2019-12-27; see also Manda and Kufaine 2013). In the words of one journalist interviewed by Malawian scholar Suzanne Temwa Gondwe Harris (2017:136): “The NGO gives money so the reporter will write. So they indirectly co-determine what is published and what is aired."

Malawian NGOs' donor-funded efforts to develop specific radio and television programs about family planning, contraception, and HIV/AIDS are longstanding, and they have adapted these efforts to transmit anti-violence messages as well (e.g., The Nation 2012-06-04; Manyozo 2008:34; National AIDS Commission 2010:66; see also Lwanda 2010:393-395, 402-403; Mhagama 2015). Examples of such programs include the popular informational radio program Uchembere Wabwino (Safe Motherhood), the radio drama Tichitenji (What Do We Do), and the television drama Tikuferanji (Why Are We Dying). The Malawian producers creatively construct 
narratives to disseminate the anti-violence messaging in ways they believe will resonate with their audience. Their narratives are usually consistent with the way international development organizations understand anti-violence scripts, but sometimes feature a unique style (Englund 2012). The national government, with financial support and under pressure from international development organizations, publishes regular monitoring reports in which they listen to the targeted radio programs and watch the targeted television programs to ensure the content does not deviate too far from the proscribed developmental scripts (e.g., National AIDS Commission 2010).

Perhaps the most striking evidence of international development organizations and their collaborating Malawian NGOs, activists, and government leaders' success in shaping domestic mass media content, though, is a simple quantitative assessment of the 2,754 newspaper articles that covered interpersonal violence in The Daily Times and The Nation between January 1, 2000 and February 14, 2016. These actors similarly extend their efforts to shape some radio and television content, but the lack of publicly available historical recordings or transcripts constrains such an analysis (Englund 2011). Figure 3 reports that there 1,517 articles that document cases of women being abused, compared to 487 articles that report cases of violence against men and 33 articles in which the victim's gender identity is not stated (e.g., babies). Additional analyses show that over 90 percent of the articles describing cases of violence against women feature only men as the perpetrators. In contrast, less than 40 percent of articles documenting incidences of violence against men list a woman as a perpetrator. Sexual forms of abuse toward women are the most prevalent, followed by cases of physical and then emotional abuse. Journalists often write derisively of male perpetrators and use article titles stating the length of their prison sentences (e.g., "Man Gets 3 Years for Assault on School Girl” in The Nation 2000-05-04). 
[Figure 3]

Other articles discuss interpersonal violence abstractly rather than focusing on specific incidences. As shown in Figure 3, there are 949 articles that critically discuss the practice of men abusing women in comparison to only 83 articles that express any level of endorsement or moral ambiguity respecting the practice of men's violence against women. Journalists glowingly describe interventions to combat gender violence that international development organizations fund; Figure 4 is one such example (The Nation 2010-12-01; see also The Daily Times 2008-0327). They further provide ample coverage of social movement activities led by domestic NGOs and supported by international development organizations, such as the 16 Days of Activism against Gender-Based Violence annual campaign started by Malawian Emma Kaliya and her colleagues (The Daily Times 2000-12-06; The Nation 2012-12-10; see African Women's Development and Communication Network 2003; 2009; MEGEN 2011; 2012; 2013; MHRRC 2007; 2013; UN Women 2015). Journalists also commonly summarize public speeches by Malawi's President and other leaders when they publicly denounce abuse (e.g., The Daily Times 2014-11-18; The Daily Times 2014-12-11), and they write opinion editorials critical of the practice (e.g., The Nation 2012-12-10). These styles of articles are broadly consistent with the journalism trainings that international and domestic NGOs lead. Articles about other forms of interpersonal violence, such as the killing of citizens with albinism, violence against LGBTQ people, and child abuse, all are in the newspapers, but they collectively appear at less than half the frequency as articles condemning the practice of men's violence against women. Among the rare articles that included expressions of moral ambiguity or outright justification of men's abuse of women, only a select few make very strong claims, like that rape within marriage was 
impossible because marriage guarantees unconditional consent and sexual access (e.g., The Nation 2006-02-27) (see Section 3 of the Online Supplement).

[Figure 4]

Overall, there are 2,093 newspaper articles that either cover specific cases of violence against women or that critically discuss the practice. ${ }^{11}$ This is about half the total number of weekdays $(4,206)$ during the time period examined. The regularity of content that implicitly or explicitly diffuses anti-violence scripts, compared with the relative scarcity of articles about other types of interpersonal violence, speaks to the power of Malawian activists, NGOs, and their international partners in shaping domestic mass media content, especially given the fact that men disproportionately dominate journalism jobs in Malawi (The Nation 2009-12-03; African Media Barometer 2012:55; Gender Links 2003; 2010).

The influence of the network of actors working to feature anti-violence messaging in the newspapers is further manifest in the temporal frequency at which anti-violence articles appear in The Daily Times and The Nation, which is depicted in Figure 5. The enactment of Malawi's first National Gender Policy in March 2000 is likely one primary reason for the substantial increase in the number of such articles during this year (Semu 2002:89). The rapid increase during late 2005 and through the first several months of 2006 is due primarily to the combined efforts of domestic activists like the Malawian lawyer Seodi White to provide journalists with material for articles because they hoped to sway public opinion and parliamentary approval in anticipation of the upcoming vote on the Protection against Domestic Violence Act, which was then successfully enacted on April 26, 2006. ${ }^{12}$ The smaller number of articles in 2004, 2007, and 2014 likely result in part from temporary lapses in foreign aid funding for domestic NGOs' 
efforts to advocate against gender violence, which include trainings for journalists (Malawi MFEPD 2017; MHRRC 2007; 2013; The Daily Times 2004-12-08). ${ }^{13}$

[Figure 5]

If journalists are responding to organizations' petitions to cover their anti-violence interventions, this should also be evident in the fine-grained data. I investigate this by focusing on a large and consistent anti-violence intervention: the activist-led and donor-funded 16 Days of Activism against Gender Violence campaign from November 25 through December 10 each year. Figure 6 includes a series of sixteen temporal graphs, one for each year between October and January, that document the weekly number of newspaper articles that criticize the practice of men's violence against women. The vertical grey section in each graph represents the period of the annual 16 Days campaign.

[Figure 6]

The graphs show that in the early years of the campaign the number of such articles published during the sixteen-day period generally was not higher than the number published during the preceding or following weeks. However, once the Protection against Domestic Violence Act passed in 2006 and the campaign gathered momentum and received financial backing from Norway and the United Nations (Malawi MFEPD 2017; MHRRC 2007; 2013), things shifted such that the number of these articles was highest during the campaign period (or the following week after journalists returned home from the campaign activities to write). There were two exceptions. In 2011, one of the newspapers elected to do a single large feature article on the campaign a few weeks later rather than a steady stream of articles (The Nation 2011-1221). And in 2012 the international NGO entitled Gender Links purposely held a workshop for journalists a month prior to the campaign, prompting an immediate uptick in articles (The Nation 
2012-11-08). The evidence in Figure 6, therefore, generally supports the conclusion that the promoters of anti-violence scripts - domestic activists and international development organizations with whom they partnered - influenced what journalists wrote about and thereby shaped newspaper content.

The large number of articles on men's violence against women should, on the one hand, be expected given that about a quarter of women in Malawi disclose experiencing such abuse on surveys (ICF 2020). Indeed, the overall frequency and temporal fluctuations in anti-violence articles likely are influenced by the abusive reality many women face. On the other hand, about half of the women who disclose on surveys that their partner abused them say they told someone about the abuse - and less than a fifth of these women went to an institutional authority for assistance rather than a close friend or family member (NSO and ICF 2017:303-304). Journalists do report on specific cases of abuse that make it to the police, and they write articles based on police press conferences in which they note increases in filed reports of men abusing women in certain districts (e.g., The Nation 2015-12-31). Still, the vast majority of abuse is silent. In the absence of Malawian activists and their international partners, it is not unimaginable that men's abuse of women would rarely make the news.

\section{Content with Patriarchal Gender Stereotypes}

Cultural scripts that portrayed women as passive objects and men as powerful aggressors also are present in the mass media found in Malawi. One important source of gender stereotypical messaging was The Weekend Times tabloid newspaper, which was an immediate success after its founding in 2009 and rapidly blossomed to a circulation on par with The Nation and The Daily Times (Englund 2011:31; Mchakulu 2018). When I met with the founding editor, Limbani Moya, he expressed great pride in the tabloid journalists' painstaking efforts to uncover 
the truth about what he saw as unreported social issues, like cases of grisly domestic abuse and adultery among political leaders, celebrities, and wealthy business owners (e.g., The Weekend Times 2009-09-04; 2013-11-11). He also acknowledged the tabloid's reliance on sexualized photographs of women's bodies, including the popular weekly full page photograph of a new “Action Girl” model. This was largely unprecedented for content in Malawi given censorship laws and conservative clothing norms for women (The Nation 2012-01-20; 2013-12-18). Overall, the tabloid's visual components and scandalous stories help it reach a broader audience, especially among heterosexual men, despite efforts by parliamentarians and other national leaders to shut it down (Nyasa Times 2012-02-21; 2012-02-24; Panapress 2010-11-04; Mchakulu 2018:12). The tabloid's portrayal of patriarchal gender stereotypes is apparent in their headlines and photographs alone, such as two examples of cover pages shown in Figure 7.

[Figure 7]

Besides the tabloid, patriarchal scripts are further diffused through foreign movies shown and sold in video parlors, the most prevalent of which during my period of analysis were - by far-Chinese martial arts and American action movies, such as the James Bond, Rambo, and Die Hard series. While viewers in other countries are accustomed to such content, many Malawians conclude that America and China must be exceptionally dangerous societies (Gray 2014:990; see also Magalasi 2015) and they worry that male viewers will become more vicious toward women (e.g., The Nation 2015-08-19). Additional movies that are available for viewing or purchase, especially in the later years of my analysis, are dramas from India and Nigeria (Li 2022). Despite being less violent, the movies still often depict women as submissive to men (Chimbuto 2016:92-98; see also Gray 2014:989). There are also reports of video parlors showing foreign pornographic films, usually in secret late at night due to strict censorship laws but other times 
more openly (The Chief Censorship Officer, Malawi Government Censorship Board 2000; The Nation 2013-08-30; The Weekend Times 2013-08-16). As with the tabloid, many people express concerns about this content, and some women may avoid video parlors because being seen there could lead to rumors and suspicion (Mpondaminga 2001). During the time period of my analysis, there was not a domestic movie industry (save a few films) nor any consistently operating movie theaters, so foreign movies dominate (Chimbuto 2016:80-81; Li 2022; Magalasi 2015; UNESCO 2021:156-158; see also The Nation 2014-11-21).

Satellite television channels also feature graphic violence alongside very gendered content, as indicated by the advertisement tagline for the popular actionX channel: "High impact action movies and series. Explosions, bombs, and bullets, flying fists and feet, dangerous men and far more dangerous women!" (Geston 2006:77; see also TVSA 2019a; 2019b). As with the video parlors, Malawians can access foreign movies via satellite channels, which again strongly steer toward action-based content given the international audience and lack of ability to follow heavy dialogue. Satellite channels also feature international reality television shows, including the very popular Big Brother Africa, which so captivated public attention that some Malawian parliamentarians temporarily banned the show for the nudity and sex scenes involving the show participant from Malawi (BBC News 2003-08-15).

Only very wealthy Malawians can afford satellite television at home, but the ubiquity of inexpensive free-to-air decoders imported from China during the middle period of my analysis, however, permitted much broader public access to satellite content (Tech Dot Africa 2010-0702). This access was abruptly cut off in late June or early July 2013, when the only company offering satellite television services in Malawi until this point, MultiChoice from South Africa, successfully updated its technology and encrypted its signals such that the free-to-air decoders no 
longer worked (Channel 24 2013-07-02; The Nation 2013-09-03; The South African 2013-08-

07). In the next few years, MultiChoice gradually rolled out service for a much cheaper satellite television subscription program, about a tenth of the price of its original service, and new competitors began operations offering inexpensive pricing (The Nation 2015-01-09).

Beyond these forms of mass media, some popular songs by Malawian and other artists, as well as commercials on the radio and television, blatantly justify men's abuse of women (Gender Links 2003; see also Englund 2011:117-118; Lwanda 2010:385-386). For example, the song Choncho Ndi Amunanga (All the Same, He is My Husband) states bluntly: "even though he beats me, I don't mind," and "beating is medicine for marriage" (Nthala 2013:187; see also Mlenga 2011). Gender stereotypes are present on the margins in other types of entertainment-based media, such as commentary by sports announcers, speeches by religious leaders, and advertisements (Gender Links 2003).

\section{Implications for Interpreting Mass Media Exposure}

Understanding content differences in the forms of mass media that Malawians can directly consume or indirectly hear about in their social environments enables me to interpret quantitative measures of mass media use more accurately. Newspaper use could expose people to a mixture of content: liberal scripts critical of men's abusive treatment of women abound in the main daily newspapers, but patriarchal scripts are prominent in The Weekend Times tabloid, which is especially popular among men. While listening to anti-violence radio programs sponsored by the national government and international donors is a clear indicator of exposure to liberal scripts, general radio consumption is more multivalent, with plenty of liberal messaging but also some patriarchal scripts in popular music and other content. Likewise, people may watch anti-violence television programs or they may prefer the more prevalent satellite content or 
foreign movies with ample portrayals of violence and gender stereotypes that are most accessible in male-dominated video parlors.

\section{THE RELATIONSHIP BETWEEN MASS MEDIA EXPOSURE AND STATED REJECTION OF MEN'S VIOLENCE AGAINST WOMEN}

Having established the potential pathways via mass media for the diffusion of different liberal and patriarchal scripts about men's abuse toward women, I next examine the reach of these scripts at the individual-level. I use logistic regression to examine the relationship between people's mass media exposure and stated rejection of such violence. Table 1 lists the descriptive statistics for the independent variables and other covariates included in my models. Combining the data across the five surveys, 80 percent of women and 86 percent of men state that men are not justified in beating their wives. There is considerable variation in the number of anti-violence newspaper articles published 30 days prior to survey respondents' personal interview dates, ranging from one to 34 with a mean of $13.47(\mathrm{SD}=6.93)$ among women and $13.84(\mathrm{SD}=6.94)$ among men. Just over 20 percent of men report at least weekly newspaper use and television use whereas slightly over ten percent of women do. Radio listening is higher: on average women report having heard just over two anti-violence radio programs in the past few months, and 48 percent of women say they listened to the radio at least weekly. Men report hearing just under three such programs on average, and 67 percent are weekly radio listeners. In what follows, I discuss the results of four main logistic regression models predicting Malawians' stated rejection of men's violence against women, each run separately for women and men. I focus my discussion on the magnitude and direction of the observed average marginal effects of independent variables capturing mass media exposure. 


\section{[Table 1]}

Newspapers

Results from the four models are provided in Table 2. Starting with Model 1, I observe average marginal effects (AMEs) of $0.005(\mathrm{CI}=0.004,0.006)$ for women and $0.003(\mathrm{CI}=0.002$, 0.004) for men for each additional anti-violence article published within the 30 days prior to when a respondent was interviewed. In other words, each anti-violence article is associated with a 0.5 (women) or 0.3 (men) percentage point increase among women in their probability of expressing rejection of men's abuse of women. Figure 8 visualizes this relationship by displaying the predicted probabilities of stated rejection by the number of anti-violence articles. Women's probability of declaring they reject abuse if only one such article had been published is 74 percent. Their probability of stated rejection gradually reaches 82 percent when 17 anti-violence articles were published and 89 percent when the maximum of 34 anti-violence articles appeared. Men's probability of stated rejection rises from 81 percent when one anti-violence article has been published to 92 percent when 34 such articles are. Stated another way, a one standard deviation increase in anti-violence articles is associated with a 3.2 (women) or 2.1 (men) percentage point increase in stated rejection. These increases are substantial and larger than, for example, those associated with the full range of educational achievement, a commonly used indicator for exposure to liberal scripts. Moreover, the results persist when disaggregating to urban or rural respondents. ${ }^{14}$ Simple bivariate models between stated rejection and anti-violence articles yield the same results (Online Supplement, Section 5, Table S4, Models 5-6). Lengthening the temporal window of included anti-violence articles published prior to a survey respondent's personal interview date from 30 to 60 or 90 days does not alter the strong positive association with stated rejection, and the number of anti-violence articles published in the 30 
days following one's survey interview is not positively associated with stated rejection (Online Supplement, Section 5, Table S4, Models 7-9).

[Table 2]

[Figure 8]

In Model 1, I also find very small AMEs for weekly newspaper use on stated objection to men's abuse of women. The associations are technically positive for women and negative for men, but the lower and upper bounds of the confidence intervals fall far onto each side of zero. These generally null results are consistent with my assessment of newspaper content being a mixed bag of anti-violence scripts (in the daily newspapers) and patriarchal gender stereotypes (in the entertainment sections of the daily newspapers and especially in The Weekend Times).

I further replicate Model 1 while adding an interaction effect between anti-violence articles and weekly newspaper use (Online Supplement, Section 5, Figure S2). Consistent with the notion that newspaper content can shape the social environment at large (e.g., Huang et al. 2021; Zaller 1992), I find no evidence of an interaction effect. The influence of anti-violence articles extends from people who potentially could have read these articles themselves—weekly newspaper users that are literate in English - to others with whom they share the information they read. However, the result is unlikely to be due solely to weekly readers having conversations with others about anti-violence scripts, particularly when considering the magnitude of the observed association. A more likely explanation is that the temporal variation in the publication of anti-violence articles is related to similar variations in other anti-violence script-sharing activities, like awareness campaigns, posters, and messaging via community leaders, all of which were prominent in urban as well as rural areas. In this sense, the measure of anti-violence articles may operate as a rough proxy for temporal variation in anti-violence script 
dissemination, broadly, across the social environment. This interpretation does not negate the importance of mass media content, but it acknowledges that to some degree it may be proxying for a range of interconnected diffusion efforts and people's discussion of them. ${ }^{15}$

In additional analyses reported in the Online Supplement (Section 5, Table S5 and Figure S3), I explore only examining articles about either: (1) specific cases of men abusing women, or (2) abstract discussions of men's violence toward women. My analyses show that, for women, both types of articles are positively associated with stated rejection. For men, though, only articles about specific cases of abuse are positively associated with stated rejection when independent measures for both types of articles are included in the model. These exploratory analyses suggest that men in Malawi may gravitate to stories that blame specific male perpetrators for particularly violent events rather than generalized condemnations of gender inequality.

\section{Radio and Television}

I next turn to the cross-sectional associations between people's stated rejection of men's violence against women and their radio and television use, respectively. Model 2 reports the association between an individual hearing anti-violence radio programs and their stated rejection. I rely only on the 2000, 2004, and 2010 surveys for this model, as the relevant questions were not asked in the final two surveys. For women, there is no noticeable association. There is for men, for whom listening to an anti-violence radio program has an AME of 0.009 (CI=0.003, 0.016), which translates to a 3.6 percentage point increase in declaring one's objection to abuse among survey respondents that listen to all four anti-violence radio programs. These results are not driven by any one of the programs. ${ }^{16}$ Interestingly, weekly radio use is associated with a 2 
percentage point increase in stated rejection for women, but a lower 0.8 percentage point increase for men (with a negative lower bound in the estimate's confidence interval).

Is hearing anti-violence radio programs associated with a higher increase in the probability of expressing rejection of men's abuse of women among those who listen to the radio regularly compared to those who do not? I replicate Model 2 and include an interaction effect between anti-violence radio programs heard and weekly radio use. To provide an accurate interpretation, I present results from interactions visually and in terms of predicted probabilities in Figure 9 (Long and Mustillo 2018). For women and men that do not use the radio weekly, there is little difference in the probability of stated rejection based on the number of anti-violence radio programs they listen to. Among weekly radio users, though, those that listen to antiviolence radio programs have higher probabilities of stated rejection than those who do not. For women, however, the difference is subtle (77.1 versus 75.0$)$. For men, this difference equates to 5.3 percentage points $(84.4$ versus 79.1$)$. Weekly radio users that listen to anti-violence radio programs would be the group most likely to have consistent exposure to the main characters in the programs and come to relate to them (see Polletta et al. 2013). Overall, though, the differences in the estimates between women and men suggest that there are likely important distinctions in the radio content they consume or how they interpret the same content.

[Figure 9]

I now turn to the relationship between individuals' expressed rejection of men's violence against women and their "television" use, which Malawians generally interpret as any content aired on domestic and satellite television stations as well as movies. As shown in Model 3, there is a small positive point estimate $(\mathrm{AME}=0.005)$ between at least weekly television use and stated rejection for women, but the confidence intervals do not merit high assurance in the direction of 
this association $(\mathrm{CI}=-0.008,0.017)$. For men, conversely, television use is associated with a 1.5 percentage point decrease in stated rejection, but the upper bound of the confidence intervals slightly extends into positive values at 0.001 . These results compliment observations that men's television consumption disproportionately favors content sustaining gender stereotypesparticularly violent foreign movies_-while women's television consumption likely exposes them to comparatively mixed content including anti-violence television programs, satellite channels, and - to a lesser extent — available movies (Gray 2011; 2014; Mchakulu 2018; Mpondaminga 2001).

Putting together insights from the content assessment, it is likely that patriarchal scripts were especially common in available television content during the time period of the 2010 survey, whereas anti-violence scripts were comparatively prevalent in available television content during the era of the 2013-14 survey. The showing of violent action movies featuring strong gender stereotypes at video parlors and on satellite television channels was widespread by the time of the 2010 survey (Gray 2011; Li 2022). MultiChoice successfully cut unpaid viewers from accessing its violent and gender-stereotypical satellite content in the summer of 2013 (Channel 24 2013-07-02; The Nation 2013-09-03; The South African 2013-08-07) and only made that service available at a much cheaper price more than a year later (The Nation 2015-01-09). And, finally, the number of dedicated shows featuring anti-violence and other liberal messaging expanded on the few domestic television stations before the 2013-14 survey (NSO 2015:56-60, 70-73).

I therefore replicate Model 3 from Table 2, but I only include respondents from the 2010 survey, followed by a second replication that only includes respondents from the 2013-14 survey. Figure 10 displays the AMEs of at least weekly television use on people's stated 
rejection of men's violence against women for these two groups of respondents. Consistent with the content assessment but nonetheless striking, the AMEs in question are negative among those surveyed in 2010 yet positive among 2013-14 respondents. ${ }^{17}$ The distinction is especially strong among men: $-0.029(\mathrm{CI}=-0.054,-0.005)$ in 2010 compared to $0.024(\mathrm{CI}=0.003,0.045)$ in 2013 14 , further supporting the axiom that changes in the content of mass media can inform and reinforce a person's moral declarations. However, there could have been other differences in television content in 2010 versus 2013-14, or differences in the unobserved characteristics of television-viewing respondents at these two time points.

[Figure 10]

The cross-sectional nature of the surveys I use means that selection processes likely explain at least part of the observed associations between stated rejection and different forms of personal mass media use, despite conditioning the models. In particular, men that are more accepting of violence might seek out opportunities to watch television content featuring gender stereotypes, which likely sustain or even strengthen their views. Conversely, those that condemn gender inequality may look to consume mass media content that they feel reflects their identity as an "enlightened" cosmopolitan who differs from those in "the village" (Swidler and Watkins 2017). Selecting one's mass media content to match prior inclinations does not erase the reinforcing power of such consumption; in fact, Zaller (1996) argues that selection processes make media most influential because the message resonates with the receiver and "hardens" their views. However, it does mean that cross-sectional models do not provide evidence of the direct causal effects of mass media.

\section{Robustness Checks}


In Model 4, I include all independent variables related to mass media exposure except the count variable for anti-violence radio programs heard (since these questions were not asked in the 2013-14 or 2015-16 surveys). The results remain largely the same as in Models 1-3. I further conduct an altered replication of Models 1-4 using district random effects instead of binary variables for each of Malawi's 28 districts (Online Supplement, Section 6, Table S6). The results are similar with subtle differences that do not alter my substantive conclusions, namely that among men the coefficients for anti-violence radio programs and weekly radio use are moderately larger while the coefficient for men's weekly television use is slightly less negative.

I also explore if the mass media variables explain part of the temporal shift toward greater stated rejection in Malawi. To do this, I conduct two altered replications of Model 4. In the first, I use a continuous measure of survey year, as opposed to a set of survey dummy variables, and I drop the mass media variables. The second is the same, but I include the mass media variables. Comparing the results from these two models, I observe that anti-violence articles explain 12.5 percent of the observed AME of time on women's stated rejection of men's violence against women and 5.1 percent of the observed AME for men. ${ }^{18}$ The variables for personal mass media do not alter the AMEs of time on stated rejection. Anti-violence articles (and the broader script-disseminating activities they may proxy for) play a role in changes over time in Malawians' moral declarations about abuse, but there must be other factors at play, each with their own distinct temporal patterns. Awareness campaigns, foreign aid projects, legislation, and changes in educational curricula — as well as their compounding power — are possible contributing factors.

\section{DISCUSSION AND CONCLUSION}


My analysis of the role of mass media in Malawians' stated rejection of men's violence against women extends a long line of sociological research on global cultural diffusion by linking macro-level processes with individual people. Focusing on the case of Malawi, I trace the diffusion pathways through mass media that bring liberal scripts condemning abuse, in addition to patriarchal scripts supporting gender stereotypes, to people in Malawi. Synthesizing information from Malawian scholars, official reports, and other sources, I summarize that domestic NGOs and activists partner with well-resourced international development organizations to host training meetings for Malawian journalists in which they promote antiviolence scripts and pay journalists for producing such content. As a result, critical coverage of men's abuse of women is high in the daily newspapers throughout the time period and often increases when international development organizations and Malawian activists are especially engaged. At the same time, entertainment media companies distribute patriarchal scripts across several mass media sources in Malawi, including but not limited to satellite television, movies, and The Weekend Times tabloid. These forms of entertainment media are comparatively popular among men.

In the statistical analysis, I show that when more anti-violence newspaper articles are published in the days leading up to when survey respondents are personally interviewed, respondents are much more likely to say they object to men's abuse of women. This relationship holds regardless of people's reports of personal newspaper usage. An additional test indicates that only articles covering specific cases of men harming women are responsible for this positive association among men, whereas for women articles critically discussing the practice of men's violence against women are also important. My analysis additionally explains that having heard anti-violence radio programs is associated with greater probabilities of stated rejection among 
men, whereas for women it is the relationship between general radio use and stated rejection that is more substantial. In contrast, I observe a negative yet somewhat noisy relationship between men's personal "television" use and their stated rejection, which is consistent with my assessment that patriarchal gender stereotypes are especially pervasive in the television shows and movies that men tend to favor. The divergent associations I uncover are not causal effects on people's moral declarations, but their consistency with my assessments of different types of mass media content suggest that exposure to anti-violence scripts increases survey respondents' likelihood of expressing that they morally oppose abuse, whereas content that also contains patriarchal gender stereotypes does not.

\section{Extending Global Cultural Diffusion to the Micro-Level}

I make one methodological and three theoretical contributions to the literature on global cultural diffusion. My approach to linking recent newspaper content to survey data using respondents' personal date of interview can be broadly applied. In most cases, the main daily newspapers for a country are now available online, so their content can be accessed and coded for relevant articles for the researchers' outcome of interest. This would be a dramatic improvement over the exclusive use of personal mass media consumption indicators, which is the current dominant approach.

Theoretically, I connect the macro-to-micro links in world society theory and developmental idealism accounts of global cultural diffusion (e.g., Frank and Meyer 2002; Thornton et al. 2015) by showing how a combination of domestic activists, NGOs, international development organizations, and entertainment media companies globally circulate liberal and patriarchal scripts to individuals. Close observation of other macro-to-micro pathways of 
diffusion beyond mass media would be similarly useful, such as education, urban environments, and aid programs.

Second, when cultural scripts are dispersed across a society, they may not reach people equally. A person's life experiences, current circumstances, and relationships inform their exposure to and understanding of different scripts. For example, in my observations, television use is negatively associated with stated rejection particularly for men, who are more likely than women to attend the video parlors that show foreign movies with patriarchal gender stereotypes tailored for a male audience. Women's mass media consumption likely differs because of the risk of being labeled as promiscuous for consuming sexualized content like The Weekend Times or being seen hanging out regularly at a video parlor. Variation across social groups can also result based on differences in their interpretation of liberal and patriarchal scripts and their different lived realities and practical challenges (McDonnell et al. 2017). For instance, I found that women's stated rejection of men's abuse of women is associated with the publication of anti-violence articles regardless of whether those articles explicitly support anti-violence scripts or implicitly do so by discussing instances of abuse. Among men, only articles about specific cases of men abusing women are positively associated with stated rejection. It could be that some men feel resentful during discussions questioning men's authority (Riley and Dodson 2016). Or some men might avoid bringing up normative arguments about gender inequality out of shame, so articles critically discussing men's abusive practices might not have stimulated supportive conversations among men. Regardless, the result highlights the importance of script resonance for different audiences, especially the powerful versus the discriminated (Davis and Robinson 1991). Observations of how people consume and discuss mass media would help clarify how different scripts and strategies of presentation resonate across social groups; they would also 
provide important details about the social life of media in Malawi, particular to what extent it is consumed in groups, as some research suggests (Englund 2011).

The third theoretical contribution I make is empirically demonstrating the importance of intermediary brokers (Pot 2019; Swidler and Watkins 2017; Wilks 2022). In Malawi, journalists' relationships with domestic NGOs, activists, and international development organizations are very important for the incorporation of anti-violence and other liberal scripts in domestic mass media. The Malawian intermediaries involved in the diffusion of foreign entertainment media also somewhat curate available content, such as the video parlor owners that decide which movies to show publicly. Research on how brokers share, block, and creatively reimagine foreign scripts within their lived realities is paramount (e.g., McDonnell 2016; Tamale 2014; Tsutsui 2018).

Despite my effort to empirically document the processes of global cultural diffusion, there are important details left unexamined. In particular, I describe some of the likely variations in patriarchal content across different forms of mass media, as well as large shifts in content availability at certain times (like satellite television), but detailed time-varying data on the circulation of patriarchal gender stereotypes in other forms of mass media content, especially television and movies, would provide greater clarity.

\section{Future Horizons for Research on Gender and Human Rights}

Besides capturing the reach of transnationally-circulated scripts regarding what people say, an especially pressing avenue for future research on global cultural diffusion at the individual-level is how exposure to such scripts shapes how people act, especially with respect to gender relations (Allendorf and Thornton 2015). Regarding men's abuse of women specifically, distinct temporal trends present a puzzling global paradox: in nearly all countries with DHS and 
other comparable survey data, people's probability of saying they reject such violence increased during the twenty-first century, but women's self-reports of being physically abused by men often remained steady and in Malawi they actually increased from 21 to 26 percent between 2004 and 2015-16 (ICF 2020). Research on the national-level conditions of "decoupling" (Meyer et al. 1997) between human rights commitments and practices offers a useful lens for thinking through this paradox. Changes in rhetorical commitments at first outpace changes in practices and the rhetoric-practice gap widens as awareness of practices that are not aligned with these commitments become more monitored (Hafner-Burton and Tsutsui 2005). Over time, that gap can narrow, particularly among democratic-leaning governments when they feel domestic and international pressure to comply with their human rights commitments and they receive aid that helps them to do so (Cole and Ramirez 2013; Sikkink 2017; Wei and Swiss 2020). Coercive compliance on matters of gender and sexuality, though, can backfire (Velasco 2020).

The paradoxical trends in moral declarations and women's self-reports of experiencing men's abuse might be following a parallel process. Many societies might be undergoing a moment of growing consciousness and openness to abuse disclosure due to the massive transmission of anti-violence scripts, such as activists in Malawi suggest is happening there (e.g., The Daily Times 2012-06-06). At the same time, actual abuse could be increasing, or at least steady, if efforts to diffuse anti-violence scripts are causing a retaliatory backlash effect. Adjudicating between these possibilities is difficult to evaluate because women face retribution for acknowledging the abuse they experience and they do not want the label of "victim" to define them (Hansen et al. 2021; Khan et al. 2018; see also Acosta 2021). Triangulating survey-based measures with data from administrative records, court case databases, and online search data and other computational sources, as well as the use of multiple methods like list experiments, in- 
depth interviews, and ethnographic observations where possible, will be crucial for deciphering between changes in reporting about violence versus actual violence (e.g., Agüero and Frisancho 2021). Overall, researchers of gender violence have made massive strides in measurement, but improvement is imperative (Heise and Hossain 2017). Finally, researchers studying social interventions to combat intimate partner violence must consider outcomes beyond moral declarations and self-reports of experiencing abuse. Even when people change their moral declarations and behaviors after being exposed to anti-violence messaging, they may not question gender hierarchies wholesale and men may use other means of controlling women (Pierotti et al. 2018).

Given the general zealousness with which many people seek to acquire and display their knowledge of the language of developmentalism in Malawi, it is an especially useful case for examining the diffusion pathways of liberal scripts. In addition, Malawi's layered cultural history is amenable to the simultaneous circulation of anti-violence scripts and patriarchal scripts given their connection to existing notions of nkhanza (unjustified abuse) and kulangiza (requisite discipline) (Chepuka et al. 2014; Johnson 2018:18-19; Nthala 2013:65; Saur et al. 2005). Future analyses in contexts with strong direct opposition to liberal scripts could yield substantially different outcomes and help identify the necessary institutional factors for diffusion to occur in the first place (Ferguson 2021). In addition, contextual factors related to gender, social class, caste, ethnicity, and socioeconomic status likely differ across contexts and could substantially alter the patterns I observe in Malawi. For example, diffusion pathways might be somewhat constrained across castes in India or linguistic groups in Indonesia. Situational dynamics are always relevant, and there are undoubtedly many stories of global cultural diffusion, not one (Watkins and Hodgson 2019). 
I uncover in this study how multiple cultural scripts about men's violence against women are disseminated through mass media to people in Malawi. International development organizations like the United Nations, domestic activists like Emma Kaliya and the NGOs they lead, as well as entertainment media companies, all work through Malawian intermediaries to spread unique scripts through mass media content to individual people. These concurrent sources of global cultural diffusion constitute a dynamic social environment in which multiple scripts about a single issue are promoted on a global scale and reach individual people. 


\section{NOTES}

1. Only Mozambique and South Africa have higher rates (ICF 2020).

2. Consistent with other studies (e.g., Tran et al. 2016), Figure 1 shows that in most countries men are more likely than women to express rejection of men's violence against women. Though men's and women's differing levels of exposure to anti-violence scripts likely play a role in this observed gender gap in moral declarations, social performance and identity likely play an especially salient factor in this area for men.

3. The Nation does publish short supplements in Chichewa and Chitumbuka biweekly, but circulation is limited and the content is very similar (Angotti et al. 2014).

4. The first Malawian show on MultiChoice satellite television began in 2017 (Nyasa Times 2017-07-28).

5. Another Malawian ethnographer similarly described casually discussing media messages with a person they met: "we then chatted a bit over this issue, saying Balaka is also the highest district affected by the AIDS as she heard from the radio" (Malawi Journals Project, 2010-04-18, Simon_100404). The Malawi Journals Project data are publicly available at: https://deepblue.lib.umich.edu/handle/2027.42/113269.

6. The researchers were Emma Bruder, Madeleine Conrad, Madeleine Danes, Samantha Galbavy, Yi Gao, Stephanie Green, Kaila Graham, Zhuang Han, Rebecca Jacobs, Trevor Orginski, Emily Schwartz, Molly Sproul, and Leah Weinstein.

7. There are 28 districts in Malawi, however, the district of Likoma Island - population of 10,714 in the 2008 census - was only included in the 2015-16 DHS and the district of Neno-population of 52,751 in 2008-was created in 2003.

8. In the 2000 DHS only one-fourth instead of one-third of men were invited to participate. In the 2013-14 MICS men ages 15-49 were invited instead of men ages 15-54.

9. Replication package: https://www.dropbox.com/s/fid0amrzzsv9p94/Pathways_20221221.zip?dl=0

10. Conversations with Emma Kaliya, Grace Kalowa, Limbani Phiri, and Victor Sindani.

11. 201 articles documented at least one case of violence against women and critically discussed the practice of such abuse.

12. Conversation with Seodi White. See also Kanyongolo and White (2017:193-194).

13. Conversations with Lugede Chiphwafu Chiumya, Emma Kaliya, Jean Mwandira, and Limbani Phiri.

14. I replicate Model 1 among urban and rural respondents separately. The AME of 0.003 for anti-violence articles among urban women is slightly smaller than the corresponding AME of 0.005 among rural women. Between rural and urban men there is no difference: both are 0.003 .

15. I am indebted to an anonymous reviewer for helping me to think through this interpretation of the results.

16. In four additional replications of Model 2, I replace my count variable for anti-violence radio programs with dichotomous variables for each of the four programs. For men, the AMEs for each of the four programs range from 0.019-0.029, whereas for women they hover around zero.

17. I further estimate the AMEs of weekly television viewing on stated rejection of men's violence against women in five replications of Model 3, one for each survey separately. 
They range from -0.006 to 0.036 for women and -0.032 to 0.024 for men. The largest differences between years are 2010 and 2014.

18. When no mass media variables are included, the AMEs for the continuous measure for survey year on stated rejection of men's abuse toward women are 0.0126048 (women) and 0.0074936 (men). After including the variables for anti-violence articles, the AMEs are reduced to 0.0110135 (women) and 0.0070802 (men). Calculating the difference between the two estimates and then dividing that by the first estimate reveals the percent of the time trend explained by anti-violence articles: 12.6 percent for women and 5.1 percent for men. 


\section{REFERENCES}

Abramsky, Tanya, Karen Devries, Ligia Kiss, Janet Nakuti, Nambusi Kyegombe, Elizabeth Starmann, Bonnie Cundill, Leilani Francisco, Dan Kaye, Tina Musuya, Lori Michau, and Charlotte Watts. 2014. "Findings from the SASA! Study: A Cluster Randomized Controlled Trial to Assess the Impact of a Community Mobilization Intervention to Prevent Violence against Women and Reduce HIV Risk in Kampala, Uganda." BMC Medicine 12(122):1-17.

Acosta, Laura. 2021. "Victimhood Dissociation and Conflict Resolution: Evidence from the Colombian Peace Plebiscite." Theory and Society.

Agüero, Jorge M., and Veronica Frisancho. 2021. "Measuring Violence against Women with Experimental Methods." Economic Development and Cultural Change.

Alesina, Alberto, Benedetta Brioschi, and Eliana La Ferrara. 2021. "Violence against Women: A Cross-Cultural Analysis for Africa." Economica 88(349):70-104.

Allendorf, Keera, and Arland Thornton. 2015. "Caste and Choice: The Influence of Developmental Idealism on Marriage Behavior." American Journal of Sociology 121(1):24387.

Angotti, Nicole, Margaret Frye, Amy Kaler, Michelle Poulin, Susan Cotts Watkins, and Sara Yeatman. 2014. "Popular Moralities and Institutional Rationalities in Malawi's Struggle against AIDS." Population and Development Review 40(3):447-73.

Angotti, Nicole, and Amy Kaler. 2013. "The More You Learn the Less You Know? Interpretive Ambiguity Across Three Modes of Qualitative Data." Demographic Research 28(33):95180.

Arias, Eric. 2019. "How Does Media Influence Social Norms? Experimental Evidence on the Role of Common Knowledge." Political Science Research and Methods 7(3):561-78.

Banerjee, Abhijit, Eliana La Ferrara, and Victor Orozco. 2019. "Entertainment, Education, and Attitudes Toward Domestic Violence." AEA Papers and Proceedings 109:133-37.

Behrman, Julia, and Margaret Frye. 2021. "Attitudes toward Intimate Partner Violence in Dyadic Perspective: Evidence from Sub-Saharan Africa.” Demography 9115955.

Bleakley, Amy, Patrick E. Jamieson, and Daniel Romer. 2012. "Trends of Sexual and Violent Content by Gender in Top-Grossing U.S. Films, 1950-2006." Journal of Adolescent Health 51(1):73-79.

Boli, John, and George M. Thomas. 1997. "World Culture in the World Polity: A Century of International Non-Governmental Organization." American Sociological Review 62(2):171.

Bonikowski, Bart. 2017. "Ethno-Nationalist Populism and the Mobilization of Collective Resentment." The British Journal of Sociology 68(S1):S181-213.

Boyle, Elizabeth Heger, Barbara J. McMorris, and Mayra Gomez. 2002. "Local Conformity to International Norms: The Case of Female Genital Cutting." International Sociology 17(1):533.

Brosius, Anna, Erika J. van Elsas, and Claes H. de Vreese. 2019. "Trust in the European Union: Effects of the Information Environment." European Journal of Communication 34(1):57-73. Charles, Maria. 2020. "Gender Attitudes in Africa: Liberal Egalitarianism Across 34 Countries." Social Forces 99(1):86-125.

Chepuka, Lignet, Miriam Taegtmeyer, Genesis Chorwe-Sungani, Janet Mambulasa, Ellen Chirwa, and Rachel Tolhurst. 2014. "Perceptions of the Mental Health Impact of Intimate Partner Violence and Health Service Responses in Malawi." Global Health Action 7(1):24816. 
Chimbuto, Joseph George Salijeni. 2016. "The Representation of Women in Nollywood Films: An Investigation of Its Impact on Audiences in Malawi." University of Roehampton.

Cole, Wade M., and Francisco O. Ramirez. 2013. "Conditional Decoupling: Assessing the Impact of National Human Rights Institutions, 1981-2004." American Sociological Review 78(4):702-25.

Cools, Sara, and Andreas Kotsadam. 2017. "Resources and Intimate Partner Violence in SubSaharan Africa." World Development 95:211-30.

Corsi, Daniel J., Jessica M. Perkins, and S. V. Subramanian. 2017. "Child Anthropometry Data Quality from Demographic and Health Surveys, Multiple Indicator Cluster Surveys, and National Nutrition Surveys in the West Central Africa Region: Are We Comparing Apples and Oranges?" Global Health Action 10(1):1328185.

Cunningham, Scott. 2021. Causal Inference: The Mixtape. New Haven: Yale University Press. Cupać, Jelena, and Irem Ebetürk. 2020. "The Personal Is Global Political: The Antifeminist Backlash in the United Nations." The British Journal of Politics and International Relations 22(4):702-14.

Davis, Nancy J., and Robert V. Robinson. 1991. “Men's and Women's Consciousness of Gender Inequality: Austria, West Germany, Great Britain, and the United States." American Sociological Review 56(1):72-84.

Ellsberg, Mary, Lori Heise, Rodolfo Pena, Sonia Agurto, and Anna Winkvist. 2001. "Researching Domestic Violence Against Women: Methodological and Ethical Considerations." Studies in Family Planning 32(1):1-16.

Elwert, Felix, and Christopher Winship. 2014. "Endogenous Selection Bias: The Problem of Conditioning on a Collider Variable." Annual Review of Sociology 40(1):31-53.

Englund, Harri. 2011. Human Rights and African Airwaves: Mediating Equality on the Chichewa Radio. Indianapolis, IN: Indiana University Press.

Ferguson, Jason L. 2021. “"There Is an Eye on Us': International Imitation, Popular Representation, and the Regulation of Homosexuality in Senegal." American Sociological Review 86(4):700-727.

Flynn, Mark A., Clay M. Craig, Christina N. Anderson, and Kyle J. Holody. 2016. "Objectification in Popular Music Lyrics: An Examination of Gender and Genre Differences." Sex Roles 75(3):164-76.

Forsyth, Selina, and Kaitlin P. Ward. 2021. "Media Use and Men's Approval of Intimate Partner Violence in Honduras.” Journal of Interpersonal Violence 0886260521993926.

Frank, David John, and John W. Meyer. 2002. "The Profusion of Individual Roles and Identities in the Postwar Period." Sociological Theory 20(1):86-105.

Frye, Margaret. 2012. "Bright Futures in Malawi's New Dawn: Educational Aspirations as Assertions of Identity." American Journal of Sociology 117(6):1565-1624.

Geldof, Marije. 2011. "Earphones Are Not for Women: Gendered ICT Use Among Youths in Ethiopia and Malawi." Information Technologies \& International Development 7(4):69-80.

Geston, Jesse. 2006. "How Has MultiChoice Africa Affected the Way People View Television in African Countries?" Master's Thesis, Grand Valley State University.

Ghaznavi, Jannath, Katherine L. Grasso, and Laramie D. Taylor. 2017. "Increasingly Violent but Still Sexy: A Decade of Central Female Characters in Top-Grossing Hollywood and Bollywood Film Promotional Material." International Journal of Communication 11:23-47.

Givens, Jennifer E., and Andrew K. Jorgenson. 2013. "Individual Environmental Concern in the World Polity: A Multilevel Analysis.” Social Science Research 42(2):418-31. 
Goetz, Anne Marie. 2020. "The New Competition in Multilateral Norm-Setting: Transnational Feminists \& the Illiberal Backlash.” Daedalus 149(1):160-79.

Gray, Jonathan. 2011. "Mobility Through Piracy, or How Steven Seagal Got to Malawi." Popular Communication 9(2):99-113.

Gray, Jonathan. 2014. "Scales of Cultural Influence: Malawian Consumption of Foreign Media." Media, Culture \& Society 36(7):982-97.

Green, Donald P. 2021. "In Search of Entertainment-Education's Effects on Attitudes and Behaviors." Pp. 195-210 in Entertainment-Education Behind the Scenes: Case Studies for Theory and Practice, edited by L. B. Frank and P. Falzone. Cham: Springer International Publishing.

Grimm, Michael, Robert Sparrow, and Luca Tasciotti. 2015. "Does Electrification Spur the Fertility Transition? Evidence from Indonesia." Demography 52(5):1773-96.

Hadler, Markus. 2017. The Influence of Global Ideas on Environmentalism and Human Rights: World Society and the Individual. London: Palgrave Macmillan.

Hafner-Burton, Emilie M., and Kiyoteru Tsutsui. 2005. "Human Rights in a Globalizing World: The Paradox of Empty Promises." American Journal of Sociology 110(5):1373-1411.

Hancioglu, Attila, and Fred Arnold. 2013. "Measuring Coverage in MNCH: Tracking Progress in Health for Women and Children Using DHS and MICS Household Surveys." PLOS Medicine 10(5):e1001391.

Hansen, Maria, Kari Stefansen, and May-Len Skilbrei. 2021. "Non-Reporting of Sexual Violence as Action: Acts, Selves, Futures in the Making." Nordic Journal of Criminology 22(1):42-57.

Harris, Suzanne Temwa. 2017. "Synthesising Media, Politics and Foreign Intervention: An Examination into Malawi's Media System Transformation.” Doctor of Philosophy in Communications, Hong Kong Baptist University.

Heise, Lori and Mazeda Hossain. 2017. STRIVE Technical Brief: Measuring Intimate Partner Violence. London, UK: London School of Hygiene and Tropical Medicine.

Hendi, Arun S. 2017. "Globalization and Contemporary Fertility Convergence." Social Forces 96(1):215-38.

Htun, Mala, and S. Laurel Weldon. 2012. "The Civic Origins of Progressive Policy Change: Combating Violence against Women in Global Perspective, 1975-2005." American Political Science Review 106(03):548-69.

Huang, Junming, Gavin Cook, and Yu Xie. 2021. "Large-Scale Quantitative Evidence of Media Impact on Public Opinion toward China." ArXiv:2012.07575 [Physics].

ICF. 2020. “The DHS Program STATcompiler.” Retrieved January 16, 2020 (http://www.statcompiler.com).

Jeong, Michelle, and Rosie Eungyuhl Bae. 2018. "The Effect of Campaign-Generated Interpersonal Communication on Campaign-Targeted Health Outcomes: A Meta-Analysis." Health Communication 33(8):988-1003.

Jepperson, Ronald, and John W. Meyer. 2011. "Multiple Levels of Analysis and the Limitations of Methodological Individualisms." Sociological Theory 29(1):54-73.

Jesmin, Syeda S., and Iftekhar Amin. 2017. "Impact of the Mass Media in Changing Attitudes towards Violence against Women in Bangladesh: Findings from a National Survey." Journal of Family Violence 32(5):525-34.

Johnson, Jessica. 2018. In Search of Gender Justice: Rights and Relationships in Matrilineal Malawi. Cambridge University Press. 
Johnson-Hanks, Jennifer A., Christine A. Bachrach, S. Phillip Morgan, Hans-Peter Kohler, and Lynette Hoelter. 2011. Understanding Family Change and Variation: Toward a Theory of Conjunctural Action. London: Springer Verlag.

Kaler, Amy, Susan Cotts Watkins, and Nicole Angotti. 2015. "Making Meaning in the Time of AIDS: Longitudinal Narratives from the Malawi Journals Project." African Journal of AIDS Research 14(4):303-14.

Kalyango, Yusuf, Folker Hanusch, Jyotika Ramaprasad, Terje Skjerdal, Mohd Safar Hasim, Nurhaya Muchtar, Mohammad Sahid Ullah, Levi Zeleza Manda, and Sarah Bomkapre Kamara. 2017. “Journalists' Development Journalism Role Perceptions.” Journalism Studies 18(5):576-94.

Kambalame, John, E. P. Chidzalo, and J. W. M. Chadangalara. 2008. Our African Way of Life (Reissued with Illustrations and a New Foreword by Dr. Desmond D. Phiri), edited by C. Young and H. K. Banda. Blantyre, Malawi: Central Africana.

Kamwendo, Gregory. 2008. "Globalization, Linguistic Diversity, and Information Dissemination in Malawi." Perspectives on Global Development and Technology 7(3-4):271-80.

Kanyongolo, Ngeyi Ruth, and Seodi White. 2017. "Legislating against the Odds: Lessons Learned from Efforts to Legislate against Marital Rape in Malawi." in The Right to Say No: Marital Rape and Law Reform in Canada, Ghana, Kenya and Malawi, edited by M. Randall, J. Koshan, and P. Nyaundi. Oxford and Portland, OR: Hart Publishing.

Katz, Elihu, and Paul F. Lazarsfeld. 1955. Personal Influence: The Part Played by People in the Flow of Mass Communications. New York, NY, US: Free Press.

Keck, Margaret E., and Kathryn Sikkink. 1998. Activists Beyond Borders: Advocacy Networks in International Politics. Ithaca, NY: Cornell University Press.

Khan, Shamus R., Jennifer S. Hirsch, Alexander Wambold, and Claude A. Mellins. 2018. "I Didn't Want to Be "That Girl": The Social Risks of Labeling, Telling, and Reporting Sexual Assault." Sociological Science 5:432-60.

Kiley, Kevin, and Stephen Vaisey. 2020. "Measuring Stability and Change in Personal Culture Using Panel Data.” American Sociological Review 85(3):477-506.

Koo, Jeong-Woo, and Jaesung Choi. 2019. "Polarized Embrace: South Korean Media Coverage of Human Rights, 1990-2016." Journal of Human Rights 18(4):455-73.

Kudo, Yuya. 2017. "Missionary Influence on Marriage Practices: Evidence from the Livingstonia Mission in Malawi.” Journal of African Economies 26(3):372-431.

Kurzman, Charles, Willa Dong, Brandon Gorman, Karam Hwang, Renee Ryberg, and Batool Zaidi. 2019. "Women's Assessments of Gender Equality.” Socius 5:2378023119872387.

Lerch, Julia C., Evan Schofer, David John Frank, Wesley Longhofer, Francisco O. Ramirez, Christine Min Wotipka, and Kristopher Velasco. 2021. "Women's Participation and Challenges to the Liberal Script: A Global Perspective." International Sociology 02685809211060911.

La Ferrara, Eliana. 2016. "Mass Media and Social Change: Can We Use Television to Fight Poverty?" Journal of the European Economic Association 14(4):791-827.

Levitt, Peggy, and Sally Engle Merry. 2011. "Making Women's Human Rights in the Vernacular: Navigating the Culture/Rights Divide.” Pp. 81-100 in Gender and Culture at the Limit of Rights, edited by D. L. Hodgson. University of Pennsylvania Press.

Li, Jiafang. 2022. "Malawians' Foreign Film Dubbing, Film Pirating and Consumption as 'Weapons of the Weak."' Journal of African Cultural Studies 34(4):357-71. 
Liebler, Carol M., Wei Jiang, and Li Chen. 2015. "Beauty, Binaries, and the Big Screen in China: Character Gender in Feature Films." Asian Journal of Communication 25(6):584-99.

Lizardo, Omar. 2017. "Improving Cultural Analysis: Considering Personal Culture in Its Declarative and Nondeclarative Modes.” American Sociological Review 82(1):88-115.

Long, J. Scott, and Sarah A. Mustillo. 2018. "Using Predictions and Marginal Effects to Compare Groups in Regression Models for Binary Outcomes.” Sociological Methods \& Research 0049124118799374.

Lwanda, John Chipembere. 2010. “'EDZI Ndi Dolo' ('AIDS Is Mighty'): Singing HIV/AIDS in Malawi, 1980-2008." Pp. 384-403 in The Culture of AIDS in Africa: Hope and Healing Through Music and the Arts, edited by G. Barz and J. M. Cohen. New York: Oxford University Press.

Lwanda, John, and Chipo Kanjo. 2013. "Computers, Culture and Music: The History of the Recording Industry in Malawi.” The Society of Malawi Journal 66(1):23-42.

Magalasi, Mufunanji. 2015. "Factors Affecting the Growth of the Malawian Film Industry." Journal of Development and Communication Studies 4(1):18-32.

Manda, Levi Zeleza, and Noel Drake Kufaine. 2013. "Starving the Messenger: A Study of Journalists' Conditions of Service in Malawi." Journal of Development and Communication Studies 2(2-3):301-311.

McDonnell, Terence E. 2010. "Cultural Objects as Objects: Materiality, Urban Space, and the Interpretation of AIDS Campaigns in Accra, Ghana." American Journal of Sociology 115(6):1800-1852.

McDonnell, Terence E. 2016. Best Laid Plans: Cultural Entropy and the Unraveling of AIDS Media Campaigns. University of Chicago Press.

McDonnell, Terence E., Christopher A. Bail, and Iddo Tavory. 2017. "A Theory of Resonance." Sociological Theory 35(1):1-14.

McDougal, Lotus, Samuel Krumholz, Nandita Bhan, Prashant Bharadwaj, and Anita Raj. 2018. "Releasing the Tide: How Has a Shock to the Acceptability of Gender-Based Sexual Violence Affected Rape Reporting to Police in India?” Journal of Interpersonal Violence 0886260518811421.

Mchakulu, Japhet Ezra July. 2018. "Mediating an Alternative Public Sphere: Malawian Readers Attitudes and Perceptions towards a Tabloid." Cogent Social Sciences 4(1):1452841.

Merry, Sally Engle. 2006. Human Rights and Gender Violence: Translating International Law into Local Justice. Chicago: University of Chicago Press.

Meyer, John W. 1986. "Myths of Socialization and Personality." Pp. 212-25 in Reconstructing Individualism: Autonomy, Individuality, and the Self in Western Thought, edited by T. C. Heller, D. E. Wellbery, and M. Sosna. Stanford, CA: Stanford University Press.

Meyer, John W., John Boli, George M. Thomas, and Francisco O. Ramirez. 1997. "World Society and the Nation-State." American Journal of Sociology 103(1):144-81.

Mhagama, Peter. 2015. "Donor Funding to Community Radio Stations in Malawi and Its Impact on Their Performance." Journal of Southern African Studies 41(6):1301-14.

Minnesota Population Center (MPC). 2019. Integrated Public Use Microdata Series, International: Version 7.2 [Machine-Readable Database]. Minneapolis, MN: University of Minnesota.

Mitchell, Maura. 2002. "'Living Our Faith': The Lenten Pastoral Letter of the Bishops of Malawi and the Shift to Multiparty Democracy, 1992-1993." Journal for the Scientific Study of Religion 41(1):5-18. 
Montoya, Celeste. 2013. From Global to Grassroots: The European Union, Transnational Advocacy, and Combating Violence against Women. Oxford: Oxford University Press.

Mood, Carina. 2010. "Logistic Regression: Why We Cannot Do What We Think We Can Do, and What We Can Do About It." European Sociological Review 26(1):67-82.

Nthala, Grant Macloly Moloko. 2013. "The Role of the Musical Arts in HIV/AIDS Intervention in Malawi." Thesis, University of the Free State.

Peters, Pauline E. 1997. "Against the Odds: Matriliny, Land and Gender in the Shire Highlands of Malawi." Critique of Anthropology 17(2):189-210.

Pierotti, Rachael S. 2013. "Increasing Rejection of Intimate Partner Violence: Evidence of Global Cultural Diffusion.” American Sociological Review 78(2):240-65.

Polletta, Francesca, Monica Trigoso, Britni Adams, and Amanda Ebner. 2013. "The Limits of Plot: Accounting for How Women Interpret Stories of Sexual Assault." American Journal of Cultural Sociology 1(3):289-320.

Pot, Hanneke. 2019. "Public Servants as Development Brokers: The Shaping of INGOs' Reducing Teenage Pregnancy Projects in Malawi’s Primary Education Sector.” Forum for Development Studies 46(1):23-44.

Rhodes, Nancy, Bridget Potocki, and Desirae S. Masterson. 2018. "Portrayals of Intimate Partner Violence in Music Videos: Effects on Perceptions of IPV Warning Signs." Media Psychology 21(1):137-56.

Riley, Emma. 2022. "Role Models in Movies: The Impact of Queen of Katwe on Students' Educational Attainment." The Review of Economics and Statistics 1-48.

Riley, Liam, and Belinda Dodson. 2016. “'Gender Hates Men': Untangling Gender and Development Discourses in Food Security Fieldwork in Urban Malawi." Gender, Place \& Culture 23(7):1047-60.

Ron, James, Shannon Golden, David Crow, and Archana Pandya. 2017. Taking Root: Human Rights and Public Opinion in the Global South. New York, NY: Oxford University Press.

Russell, S. Garnett, Julia C. Lerch, and Christine Min Wotipka. 2018. "The Making of a Human Rights Issue: A Cross-National Analysis of Gender-Based Violence in Textbooks, 19502011." Gender \& Society 32(5):713-38.

Saur, Maria, Linda Semu, and Stella Hauya Ndau. 2005. Nkhanza: Listening to People's Voices. Zomba, Malawi: Kachere Series.

Semu, Linda. 2002. 'Kamuzu's Mbumba: Malawi Women's Embeddedness to Culture in the Face of International Political Pressure and Internal Legal Change.” Africa Today 49(2):7799.

Sicard, S. V. 2000. "The Arrival of Islam in Malawi and the Muslim Contribution to Development." Journal of Muslim Minority Affairs 20(2):291-311.

Sikkink, Kathryn. 2017. Evidence for Hope: Making Human Rights Work in the 21st Century. Princeton, NJ: Princeton University Press.

Small, Mario Luis. 2011. "How to Conduct a Mixed Methods Study: Recent Trends in a Rapidly Growing Literature." Annual Review of Sociology 37(1):57-86.

Solovei, Adriana, and Bas van den Putte. 2020. "The Effects of Five Public Information Campaigns: The Role of Interpersonal Communication.” Communications 45(s1):586-602.

Swidler, Ann, and Susan Watkins. 2015. "Practices of Deliberation in Rural Malawi." Pp. 13366 in Deliberation and Development: Rethinking the Role of Voice and Collective Action in Unequal Societies, Equity and Development. The World Bank. 
Swidler, Ann, and Susan Cotts Watkins. 2017. A Fraught Embrace: The Romance and Reality of AIDS Altruism in Africa. Princeton, NJ: Princeton University Press.

Tamale, Sylvia. 2014. "Exploring the Contours of African Sexualities: Religion, Law and Power." African Human Rights Law Journal 14(1):150-77.

Taulo, John L., Kenneth Joseph Gondwe, and Adoniya Ben Sebitosi. 2015. "Energy Supply in Malawi: Options and Issues.” Journal of Energy in Southern Africa 26(2):19-32.

Thornton, Arland. 2005. Reading History Sideways: The Fallacy and Enduring Impact of the Developmental Paradigm on Family Life. Chicago, IL: University of Chicago Press.

Thornton, Arland, Georgina Binstock, Mohammad Jalal Abbasi-Shavazi, Dirgha Ghimire, Arjan Gjonca, Attila Melegh, Colter Mitchell, Mansoor Moaddel, Yu Xie, Li-shou Yang, Linda Young-DeMarco, and Kathryn M. Yount. 2012. "Knowledge and Beliefs About National Development and Developmental Hierarchies: The Viewpoints of Ordinary People in Thirteen Countries." Social Science Research 41(5):1053-68.

Thornton, Arland, Shawn F. Dorius, and Jeffrey Swindle. 2015. "Developmental Idealism: The Cultural Foundations of World Development Programs." Sociology of Development 1(2):277-320.

Tran, Thach Duc, Hau Nguyen, and Jane Fisher. 2016. "Attitudes towards Intimate Partner Violence against Women among Women and Men in 39 Low- and Middle-Income Countries." PLOS ONE 11(11):e0167438.

Trinitapoli, Jenny, and Alexander Weinreb. 2012. Religion and AIDS in Africa. New York, NY: Oxford University Press.

Tsutsui, Kiyoteru. 2018. Rights Make Might: Global Human Rights and Minority Social Movements in Japan. New York, NY: Oxford University Press.

United Nations (UN). 1993. A/RES/48/104. Declaration on the Elimination of Violence against Women.

United Nations (UN). 1995. Report of the Fourth World Conference on Women. Beijing.

United Nations (UN). 2021. "United Nations Treaty Collection Status of Treaties: Convention on the Elimination of All Forms of Discrimination against Women New York, 18 December 1979." Retrieved January 20, 2021 (https://treaties.un.org/Pages/ViewDetails.aspx?src=TREATY\&mtdsg_no=IV8\&chapter=4\&lang=en).

Velasco, Kristopher. 2020. “A Growing Queer Divide: The Divergence between Transnational Advocacy Networks and Foreign Aid in Diffusing LGBT Policies.” International Studies Quarterly 64(1):120-32.

Velasco, Kristopher. Forthcoming. "Queering the World Society: Global Norms, Rival Transnational Networks, and the Contested Case of LGBT Rights.” American Journal of Sociology.

de Vreese, Claes H., Mark Boukes, Andreas Schuck, Rens Vliegenthart, Linda Bos, and Yph Lelkes. 2017. "Linking Survey and Media Content Data: Opportunities, Considerations, and Pitfalls." Communication Methods and Measures 11(4):221-44.

Wang, Lili. 2018. "Influences of Media Exposure on Chinese University Students' Attitudes and Perceptions of Intimate Partner Violence.” Deviant Behavior 39(9):1202-16.

Ward, L. Monique. 2016. "Media and Sexualization: State of Empirical Research, 1995-2015." The Journal of Sex Research 53(4-5):560-77.

Ward, L. Monique, and Petal Grower. 2020. "Media and the Development of Gender Role Stereotypes." Annual Review of Developmental Psychology 2(1):177-99. 
Watkins, Susan Cotts, and Dennis Hodgson. 2019. "Developmental Idealism, the International Population Movement, and the Transformation of Population Ideology in Kenya." Sociology of Development 5(3):229-47.

Wei, Qian, and Liam Swiss. 2020. "Filling Empty Promises? Foreign Aid and Human Rights Decoupling, 1981-2011." The Sociological Quarterly 0(0):1-20.

Wilks, Mary-Collier. 2022. "Embodying Feminism: Donor Demands and Bridgework in Cambodian Nongovernmental Organizations." Gender, Work \& Organization 29(2):575-90.

Wimmer, Andreas. 2021. "Domains of Diffusion: How Culture and Institutions Travel around the World and with What Consequences.” American Journal of Sociology 126(6):1389-1438.

Winkler, Stephen. 2021. "Media's Influence on LGBTQ Support Across Africa." British Journal of Political Science 51(2):807-26.

World Bank. 2019. "Power Outages in Firms in a Typical Month (Number) - Malawi." Databank. Retrieved February 11, 2019 (https://data.worldbank.org/indicator/IC.ELC.OUTG?locations=MW).

World Bank. 2021. "Women, Business and the Law Database." Retrieved January 20, 2021 (https://wbl.worldbank.org/en/wbl-data).

Zaller, John. 1992. The Nature and Origins of Mass Opinion. Cambridge, England: Cambridge University Press. 


\section{TABLES}

Table 1. Descriptive statistics for all variables.

\begin{tabular}{|c|c|c|c|c|c|c|c|c|c|c|}
\hline & \multicolumn{5}{|c|}{ Women $(\mathrm{N}=96,730)$} & \multicolumn{5}{|c|}{ Men $(\mathrm{N}=27,848)$} \\
\hline & $\%$ & Mean & S.D. & Min & Max & $\%$ & Mean & S.D. & Min & Max \\
\hline \multicolumn{11}{|l|}{ Dependent Variable } \\
\hline $\begin{array}{l}\text { Stated Rejection of Men's Violence } \\
\text { against Women }\end{array}$ & 80.29 & & & 0 & 1 & 85.97 & & & 0 & 1 \\
\hline \multicolumn{11}{|l|}{ Independent Variables } \\
\hline Anti-Violence Articles & & 13.47 & 6.93 & 1 & 34 & & 13.84 & 6.94 & 1 & 34 \\
\hline Newspaper Weekly & 10.38 & & & 0 & 1 & 20.91 & & & 0 & 1 \\
\hline Anti-Violence Radio Programs & & 2.07 & 1.72 & 0 & 4 & & 2.89 & 1.44 & 0 & 4 \\
\hline Radio Weekly & 47.67 & & & 0 & 1 & 67.31 & & & 0 & 1 \\
\hline Television Weekly & 11.61 & & & 0 & 1 & 22.80 & & & 0 & 1 \\
\hline \multicolumn{11}{|l|}{ Covariates } \\
\hline Education & & 5.30 & 3.70 & 0 & 13 & & 6.62 & 3.67 & 0 & 13 \\
\hline Urban & 17.55 & & & 0 & 1 & 19.56 & & & 0 & 1 \\
\hline Christian & 85.03 & & & 0 & 1 & 83.98 & & & 0 & 1 \\
\hline Household Wealth & & 2.08 & 1.44 & 0 & 5 & & 2.21 & 1.41 & 0 & 5 \\
\hline Matrilineal & 77.28 & & & 0 & 1 & 77.70 & & & 0 & 1 \\
\hline \multicolumn{11}{|l|}{ Marital History } \\
\hline Never Partnered & 19.37 & & & 0 & 1 & 37.28 & & & 0 & 1 \\
\hline Formerly Partnered & 12.81 & & & 0 & 1 & 3.55 & & & 0 & 1 \\
\hline Currently Partnered: Monogamy & 58.08 & & & 0 & 1 & 54.18 & & & 0 & 1 \\
\hline Currently Partnered: Polygamy & 9.74 & & & 0 & 1 & 4.99 & & & 0 & 1 \\
\hline Age & & 28.03 & 9.22 & 15 & 49 & & 28.82 & 10.33 & 15 & 54 \\
\hline
\end{tabular}


Note: Statistics include data from the 2000, 2004, 2010, and 2015-16 Malawi Demographic and Health Surveys, the 2013-14 Malawi Multiple Indicator Cluster Survey, and the author's dataset of Malawian newspaper articles about interpersonal violence. The one exception is anti-violence radio programs, which was only asked on the first three surveys. Correlation matrices for all variables are in the Online Supplement (Section 3, Tables S2 and S3). 
Table 2. Average marginal effects with 95 percent confidence intervals from logistic regression models predicting stated rejection of men's violence against women.

\begin{tabular}{|c|c|c|c|c|c|c|c|c|}
\hline & \multicolumn{2}{|c|}{ Model 1} & \multicolumn{2}{|c|}{ Model 2} & \multicolumn{2}{|c|}{ Model 3} & \multicolumn{2}{|c|}{ Model 4} \\
\hline & Women & Men & Women & Men & Women & Men & Women & Men \\
\hline \multirow[t]{2}{*}{ Anti-Violence Articles } & $0.005^{* * *}$ & $0.003^{* * *}$ & & & & & $0.005^{* * *}$ & $0.003^{* * * *}$ \\
\hline & {$[0.004,0.006]$} & {$[0.002,0.004]$} & & & & & {$[0.004,0.006]$} & {$[0.002,0.004]$} \\
\hline \multirow[t]{2}{*}{ Newspaper Weekly } & 0.006 & -0.004 & & & & & 0.004 & -0.003 \\
\hline & {$[-0.006,0.018]$} & {$[-0.018,0.010]$} & & & & & {$[-0.008,0.016]$} & {$[-0.017,0.011]$} \\
\hline \multirow{2}{*}{$\begin{array}{l}\text { Anti-Violence Radio } \\
\text { Programs }\end{array}$} & & & 0.000 & $0.009^{* *}$ & & & & \\
\hline & & & {$[-0.003,0.004]$} & {$[0.003,0.016]$} & & & & \\
\hline \multirow[t]{2}{*}{ Radio Weekly } & & & $0.020^{* * * *}$ & 0.008 & & & $0.009^{*}$ & 0.011 \\
\hline & & & {$[0.010,0.031]$} & {$[-0.012,0.029]$} & & & {$[0.002,0.017]$} & {$[-0.001,0.023]$} \\
\hline \multirow[t]{2}{*}{ Television Weekly } & & & & & 0.005 & -0.015 & 0.003 & -0.014 \\
\hline & & & & & {$[-0.008,0.017]$} & {$[-0.030,0.001]$} & {$[-0.010,0.016]$} & {$[-0.030,0.002]$} \\
\hline \multirow[t]{2}{*}{ Education } & $0.008^{* * *}$ & $0.005^{* * *}$ & $0.008^{* * *}$ & $0.005^{* * *}$ & $0.009^{* * *}$ & $0.006^{* * *}$ & $0.008^{* * *}$ & $0.005^{* * *}$ \\
\hline & {$[0.007,0.010]$} & {$[0.004,0.007]$} & {$[0.006,0.009]$} & {$[0.003,0.008]$} & {$[0.008,0.010]$} & {$[0.004,0.007]$} & {$[0.007,0.009]$} & {$[0.004,0.007]$} \\
\hline \multirow[t]{2}{*}{ Urban } & $0.034^{* * *}$ & 0.017 & $0.040^{* * *}$ & 0.032 & $0.038^{* * *}$ & $0.023^{*}$ & $0.034^{* * *}$ & $0.020^{*}$ \\
\hline & {$[0.020,0.048]$} & {$[-0.003,0.037]$} & {$[0.020,0.060]$} & {$[-0.000,0.064]$} & {$[0.024,0.052]$} & {$[0.004,0.042]$} & {$[0.019,0.048]$} & {$[0.000,0.039]$} \\
\hline \multirow[t]{2}{*}{ Christian } & 0.004 & 0.011 & 0.002 & 0.017 & 0.002 & 0.012 & 0.004 & 0.011 \\
\hline & {$[-0.008,0.016]$} & {$[-0.006,0.029]$} & {$[-0.015,0.018]$} & {$[-0.008,0.043]$} & {$[-0.010,0.014]$} & {$[-0.006,0.029]$} & {$[-0.008,0.016]$} & {$[-0.006,0.028]$} \\
\hline \multirow[t]{2}{*}{ Wealth } & $0.006^{* * *}$ & $0.006^{* *}$ & 0.004 & 0.005 & $0.009^{* * *}$ & $0.007^{* *}$ & $0.008^{* * *}$ & $0.006^{* *}$ \\
\hline & {$[0.003,0.009]$} & {$[0.002,0.011]$} & {$[-0.001,0.008]$} & {$[-0.002,0.012]$} & {$[0.008,0.010]$} & {$[0.003,0.011]$} & {$[0.007,0.009]$} & {$[0.002,0.011]$} \\
\hline \multirow[t]{2}{*}{ Matrilineal } & 0.010 & 0.003 & 0.001 & 0.015 & 0.010 & 0.004 & 0.009 & 0.003 \\
\hline & {$[-0.002,0.021]$} & {$[-0.014,0.021]$} & {$[-0.014,0.017]$} & {$[-0.012,0.042]$} & {$[-0.001,0.022]$} & {$[-0.013,0.022]$} & {$[-0.002,0.021]$} & {$[-0.014,0.020]$} \\
\hline \multicolumn{9}{|l|}{ Partnership History } \\
\hline \multicolumn{9}{|l|}{ Never (Omitted) } \\
\hline \multirow[t]{2}{*}{ Formerly Partnered } & $0.041^{* * *}$ & 0.011 & $0.067^{* * *}$ & 0.021 & $0.040^{* * *}$ & 0.010 & $0.043^{* * *}$ & 0.011 \\
\hline & {$[0.029,0.054]$} & {$[-0.021,0.043]$} & {$[0.048,0.085]$} & {$[-0.028,0.069]$} & {$[0.027,0.053]$} & {$[-0.022,0.042]$} & {$[0.030,0.055]$} & {$[-0.021,0.043]$} \\
\hline \multirow{2}{*}{$\begin{array}{l}\text { Currently Partnered: } \\
\text { Monogamy }\end{array}$} & $0.042^{* * *}$ & $0.055^{* * *}$ & $0.060^{* * *}$ & $0.058^{* * *}$ & $0.040^{* * *}$ & $0.054^{* * *}$ & $0.041^{* * *}$ & $0.054^{* * *}$ \\
\hline & {$[0.031,0.052]$} & {$[0.039,0.070]$} & {$[0.045,0.074]$} & {$[0.034,0.082]$} & {$[0.030,0.050]$} & {$[0.039,0.070]$} & {$[0.031,0.051]$} & {$[0.038,0.070]$} \\
\hline \multirow{2}{*}{$\begin{array}{l}\text { Currently Partnered: } \\
\text { Polygamy }\end{array}$} & $0.027^{* * *}$ & -0.000 & $0.054^{* * *}$ & -0.002 & $0.025^{* * *}$ & -0.002 & $0.026^{* * *}$ & -0.002 \\
\hline & {$[0.013,0.040]$} & {$[-0.032,0.031]$} & {$[0.035,0.073]$} & {$[-0.048,0.044]$} & {$[0.011,0.039]$} & {$[-0.033,0.030]$} & {$[0.013,0.040]$} & {$[-0.033,0.030]$} \\
\hline \multirow[t]{2}{*}{ Age } & $0.003^{* * *}$ & $0.004^{* * * *}$ & $0.003^{* * *}$ & $0.003^{* * *}$ & $0.003^{* * *}$ & $0.004^{* * *}$ & $0.003^{* * *}$ & $0.004^{* * * *}$ \\
\hline & {$[0.003,0.004]$} & {$[0.003,0.005]$} & {$[0.003,0.004]$} & {$[0.002,0.005]$} & {$[0.003,0.004]$} & {$[0.003,0.005]$} & {$[0.003,0.004]$} & {$[0.003,0.005]$} \\
\hline
\end{tabular}




\begin{tabular}{|c|c|c|c|c|c|c|c|c|}
\hline Survey Variables & Yes & Yes & Yes & Yes & Yes & Yes & Yes & Yes \\
\hline District Variables & Yes & Yes & Yes & Yes & Yes & Yes & Yes & Yes \\
\hline Respondents (N) & 96398 & 27770 & 47738 & 13473 & 96510 & 27793 & 96267 & 27719 \\
\hline
\end{tabular}

Note: Data are from the 2000, 2004, 2010, and 2015-16 Malawi Demographic and Health Surveys, the 2013-14 Malawi Multiple Indicator Cluster Survey, and the author's dataset of Malawian newspaper articles about interpersonal violence. Two-tailed significance tests (p-value): *.05,**.01,***.001. 


\section{FIGURES}

Figure 1. Stated rejection of men's violence against women is increasing across most societies worldwide.

Women

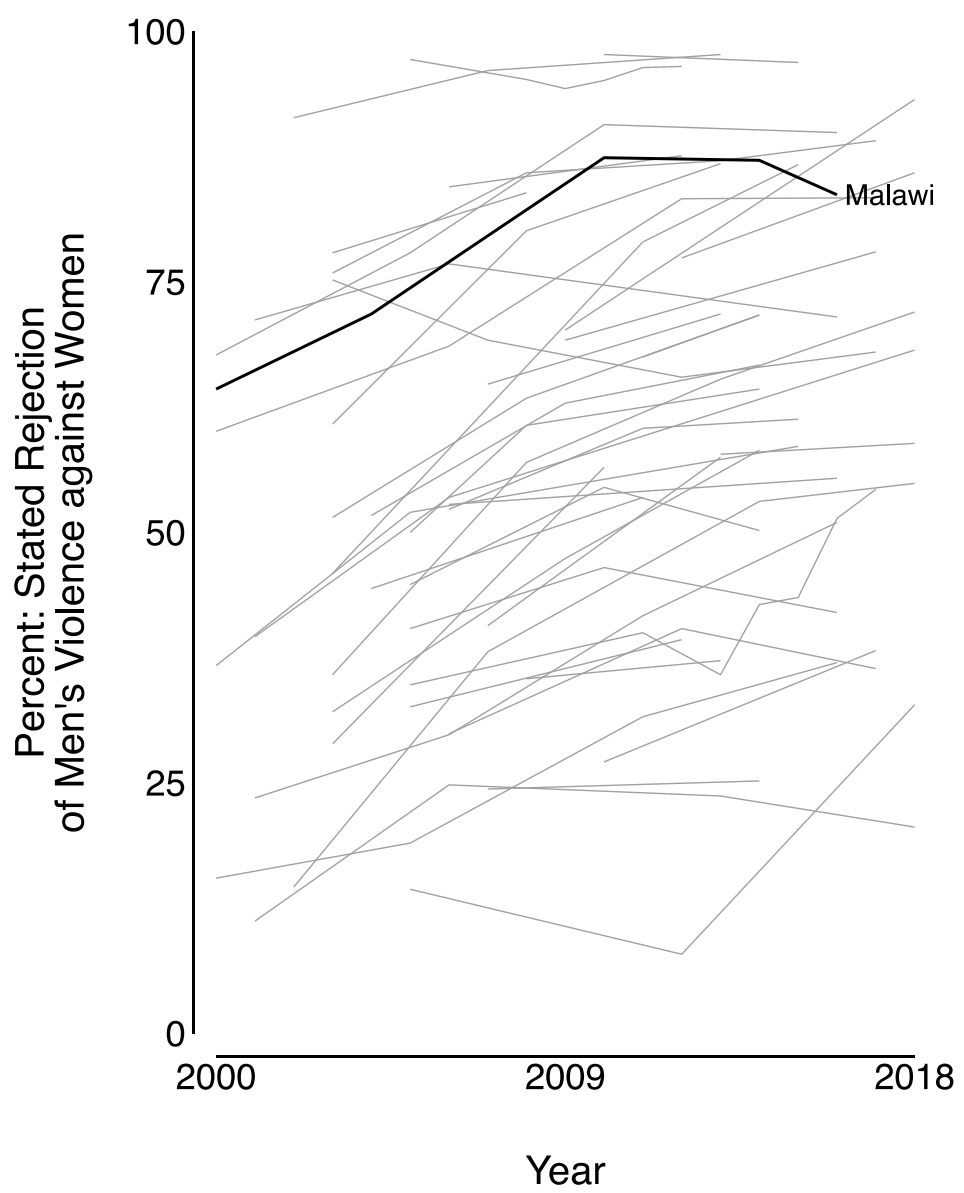

Men

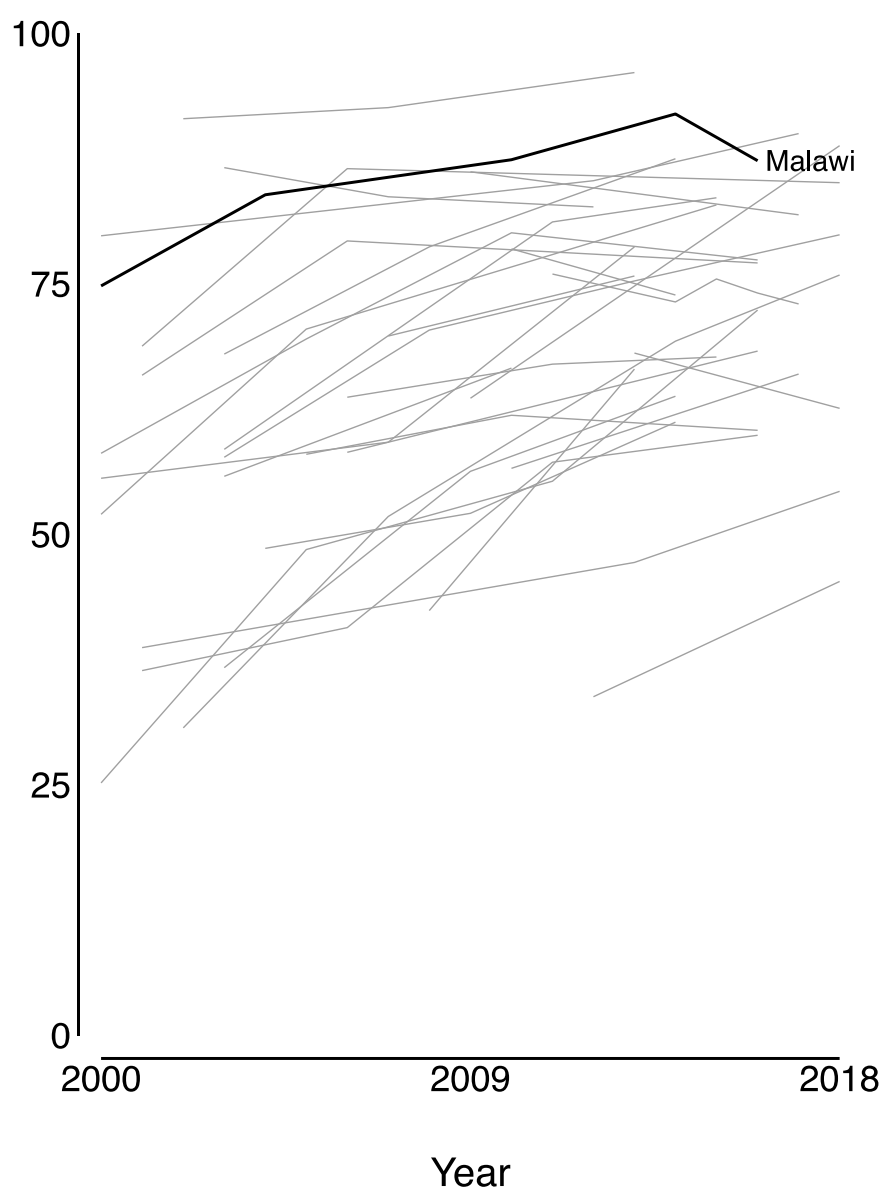

Note: Data are from Statcompiler, which aggregates estimates from the cross-national Demographic and Health Surveys (ICF 2020) with additional data from the 2013-14 Multiple Indicator Cluster Survey in Malawi. Individual lines represent countries, including Malawi and 44 other countries across Africa, Asia, Central and South America, and Eastern Europe (see Section 1 of the Online Supplement). 
Figure 2. Cross-national trends in at least weekly newspaper, radio, and television use.
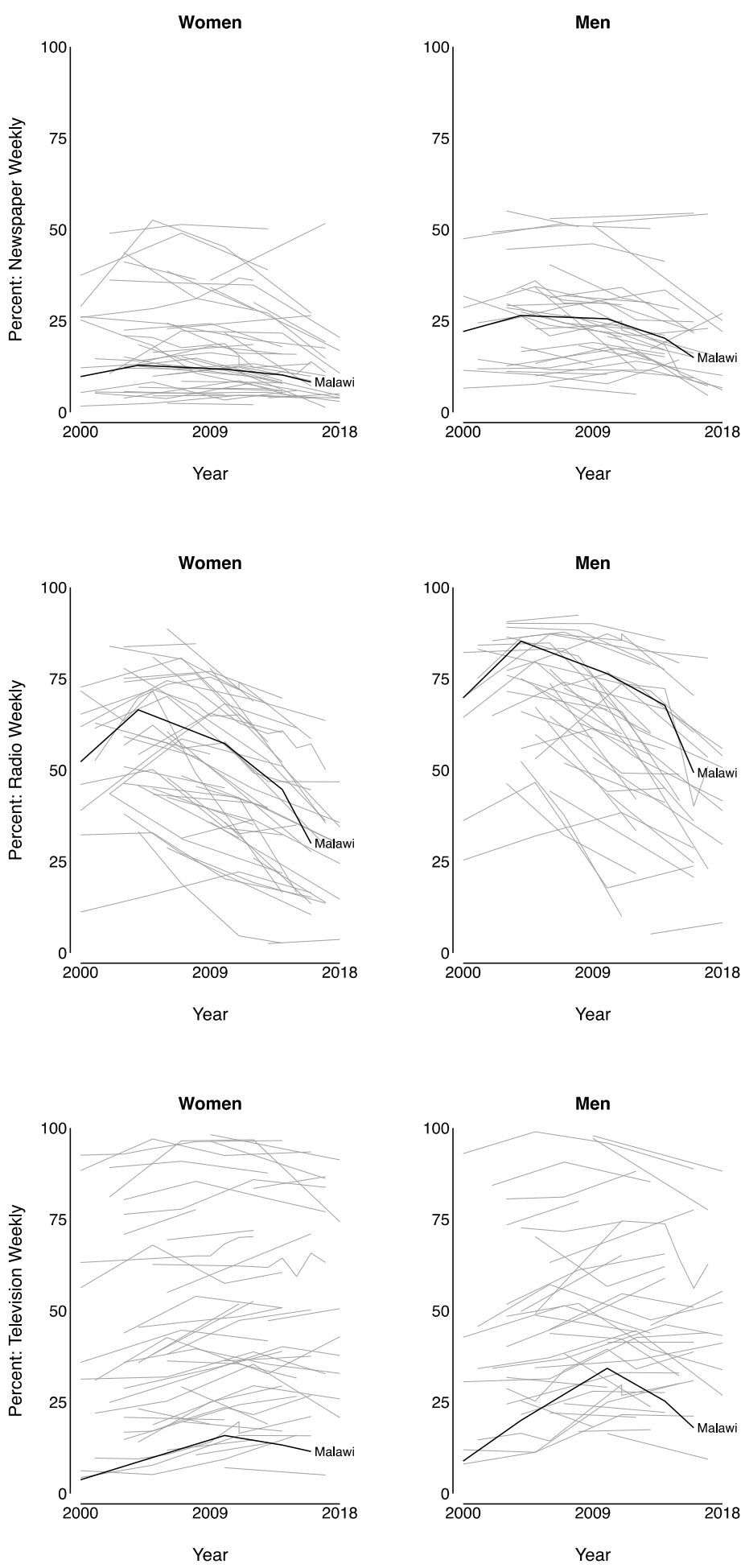

Note: Data are from Statcompiler, which aggregates estimates from the cross-national Demographic and Health Surveys (ICF 2020) with additional data from the 2013-14 Multiple Indicator Cluster Survey in Malawi. Individual lines represent countries, including Malawi and 48 other countries across Africa, Asia, Central and South America, and Eastern Europe (see Section 1 of the Online Supplement). 
Figure 3. The frequency of newspaper articles about men's violence against women far outweighs the frequency of newspaper articles about other forms of interpersonal violence.

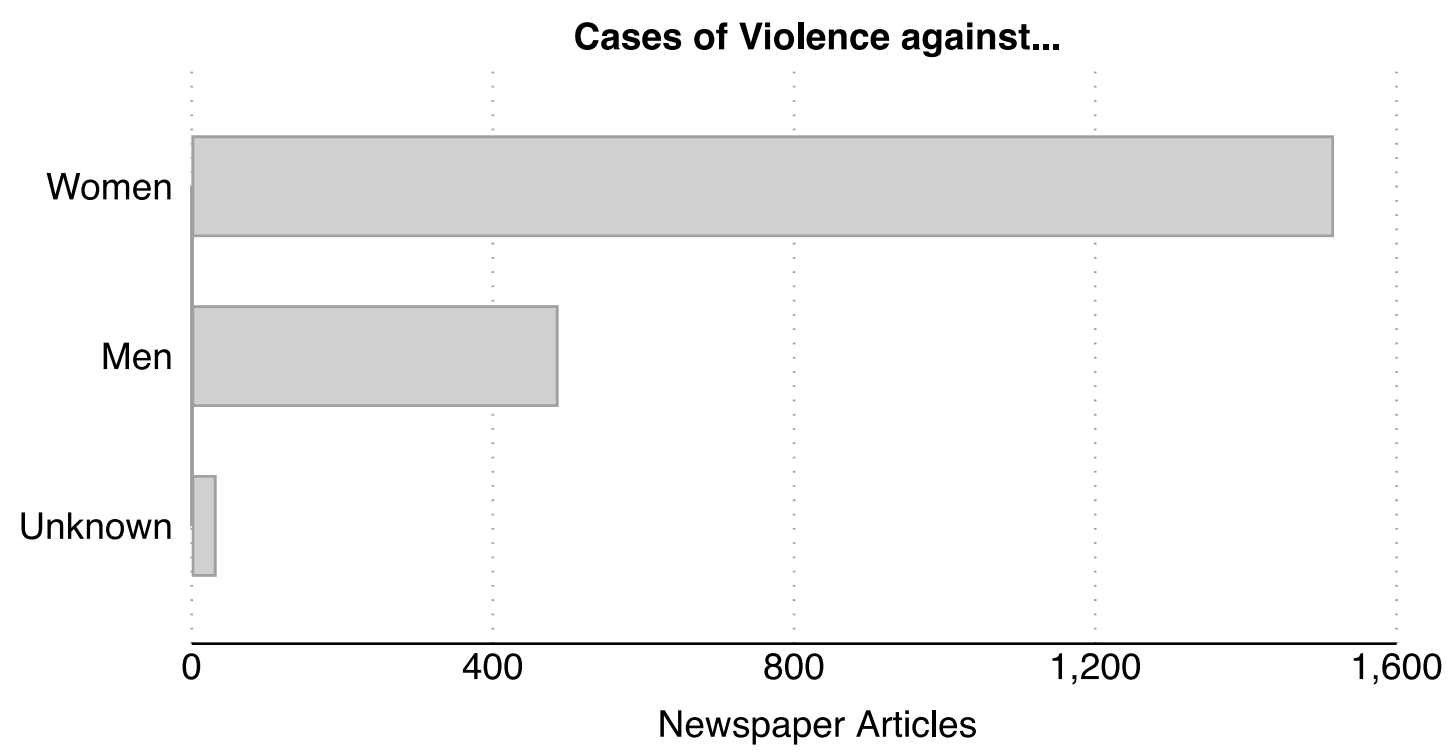

Discussion of Campaigns or Opinion Editorials that...

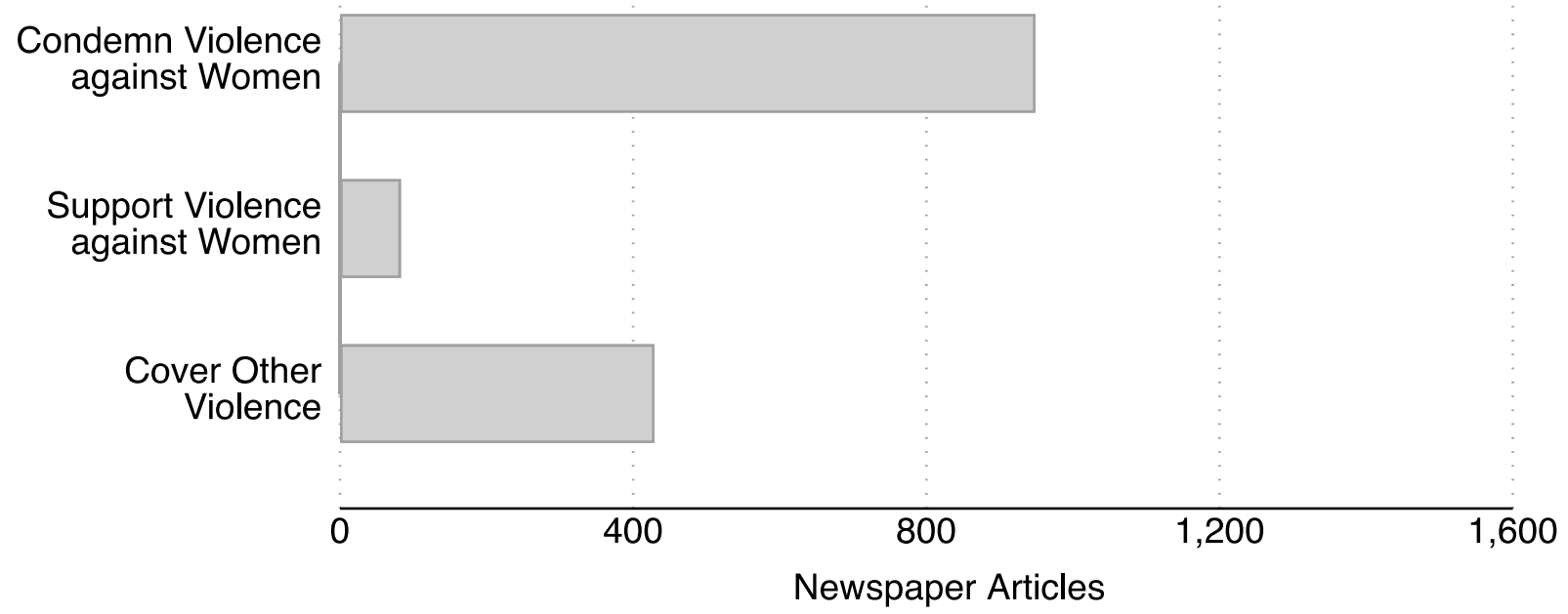

Note: Data are from author's dataset of Malawian newspaper articles about interpersonal violence, specifically from weekday editions of The Nation and The Daily Times between January 1, 2000 and February 14, 2016. 
Figure 4. Example of a newspaper article positively reporting on NGO activities to combat gender violence.

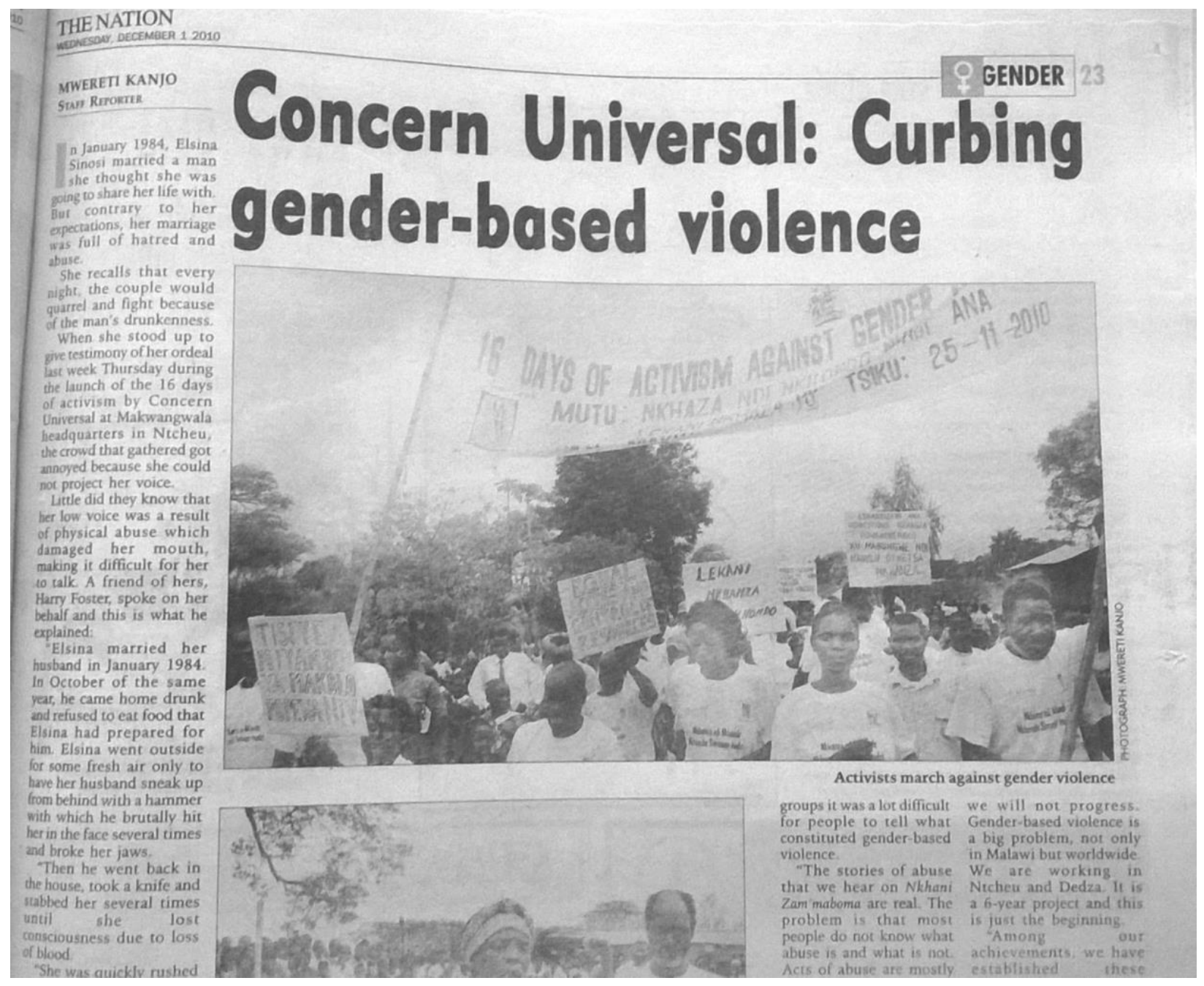

Note: The Nation, December 1, 2010. 
Figure 5. Monthly frequency of anti-violence articles in The Nation and The Daily Times.

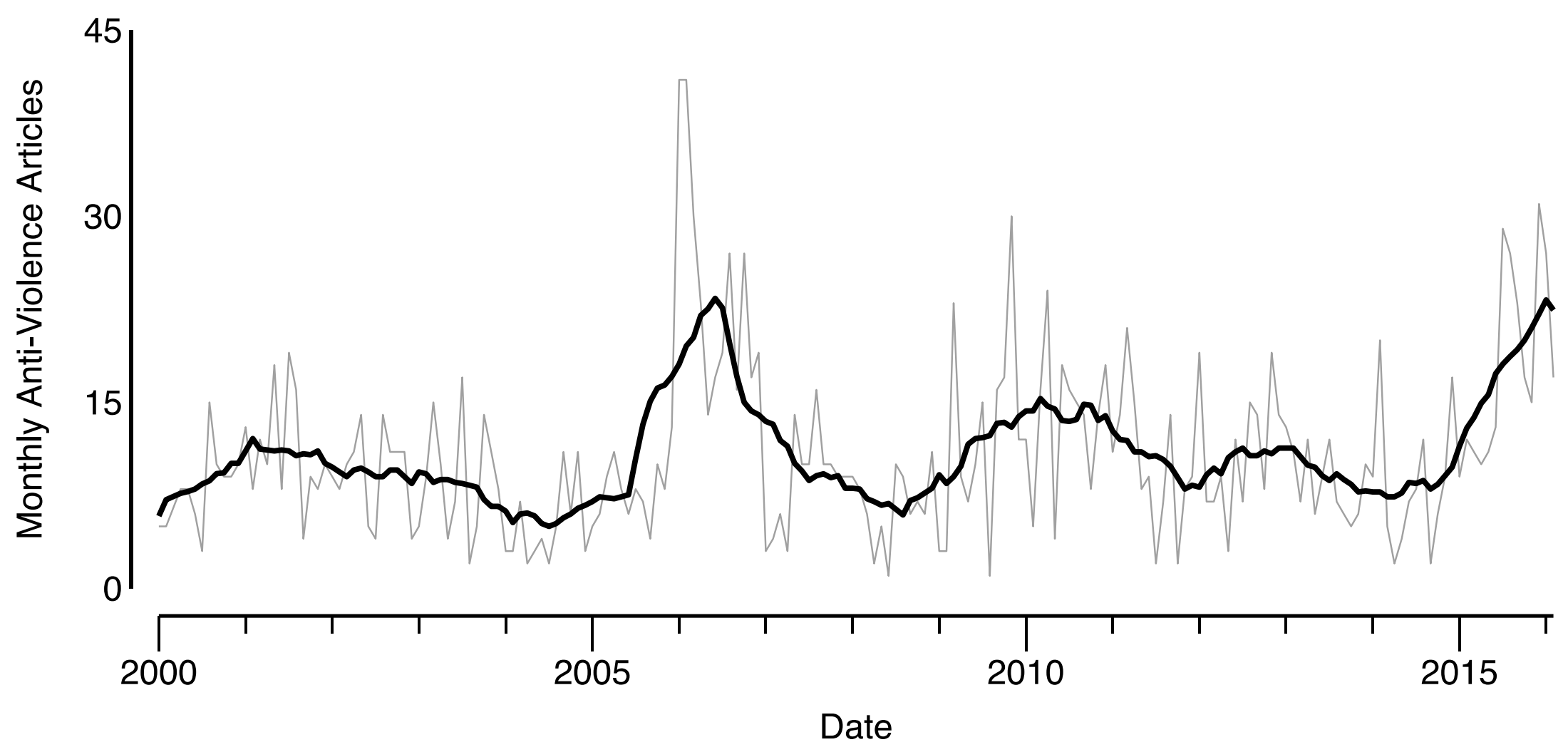

\section{Raw Smoothed}

Note: Data are from author's dataset of Malawian newspaper articles about interpersonal violence, specifically from weekday editions of The Nation and The Daily Times between January 1, 2000 and February 14, 2016. Smoothed totals are averaged across a period of 13 months: 6 months before and after a given month. 
Figure 6. Since 2006, newspaper articles critical of the practice of men's violence against women were especially prevalent during and immediately following the 16 Days of Activism against Gender Violence annual campaigns.
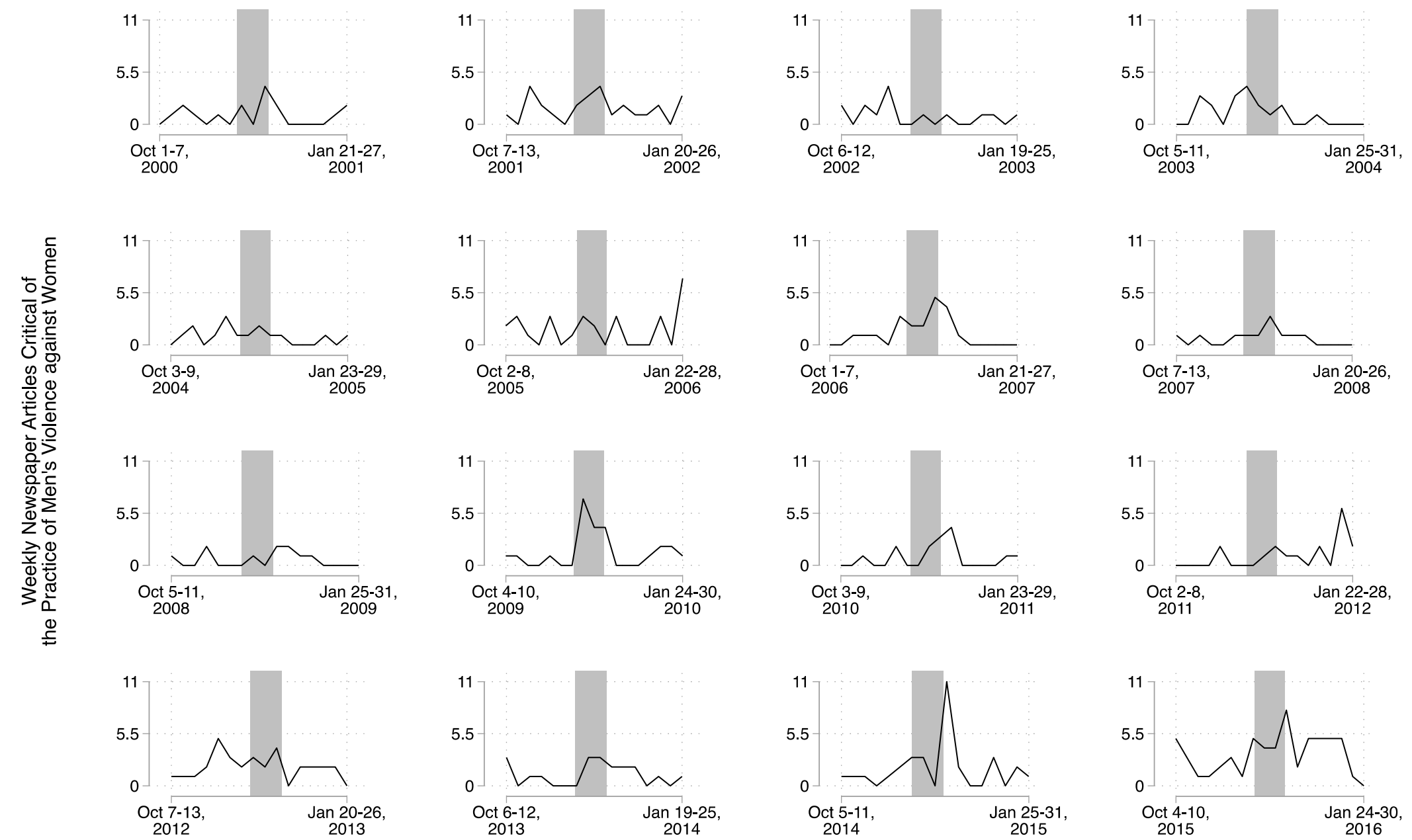

Date

Note: Data are from author's dataset of Malawian newspaper articles about interpersonal violence, specifically from weekday editions of The Nation and The Daily Times between January 1, 2000 and February 14, 2016. 
Figure 7. Two example cover pages of The Weekend Times tabloid with patriarchal gender stereotypes.
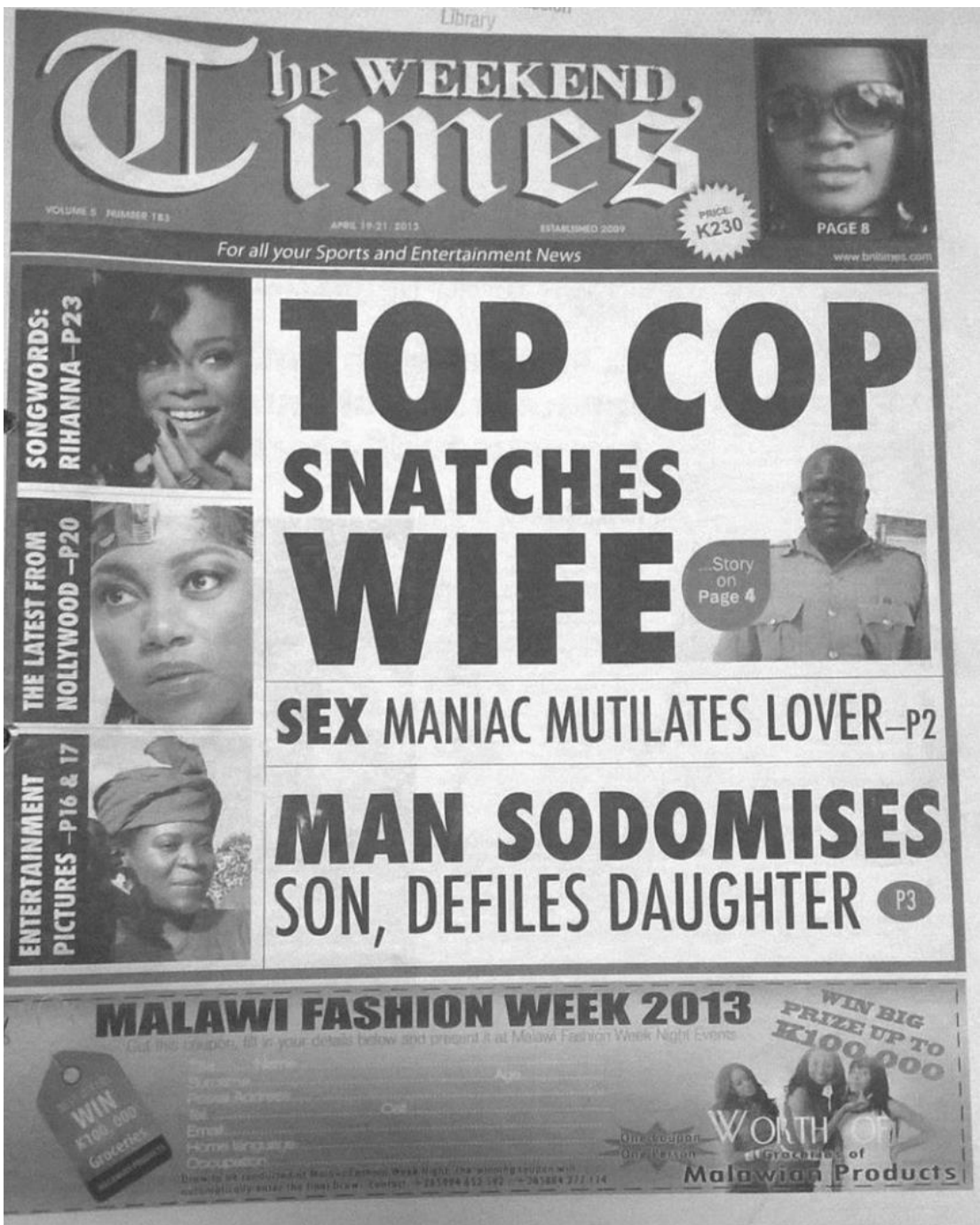

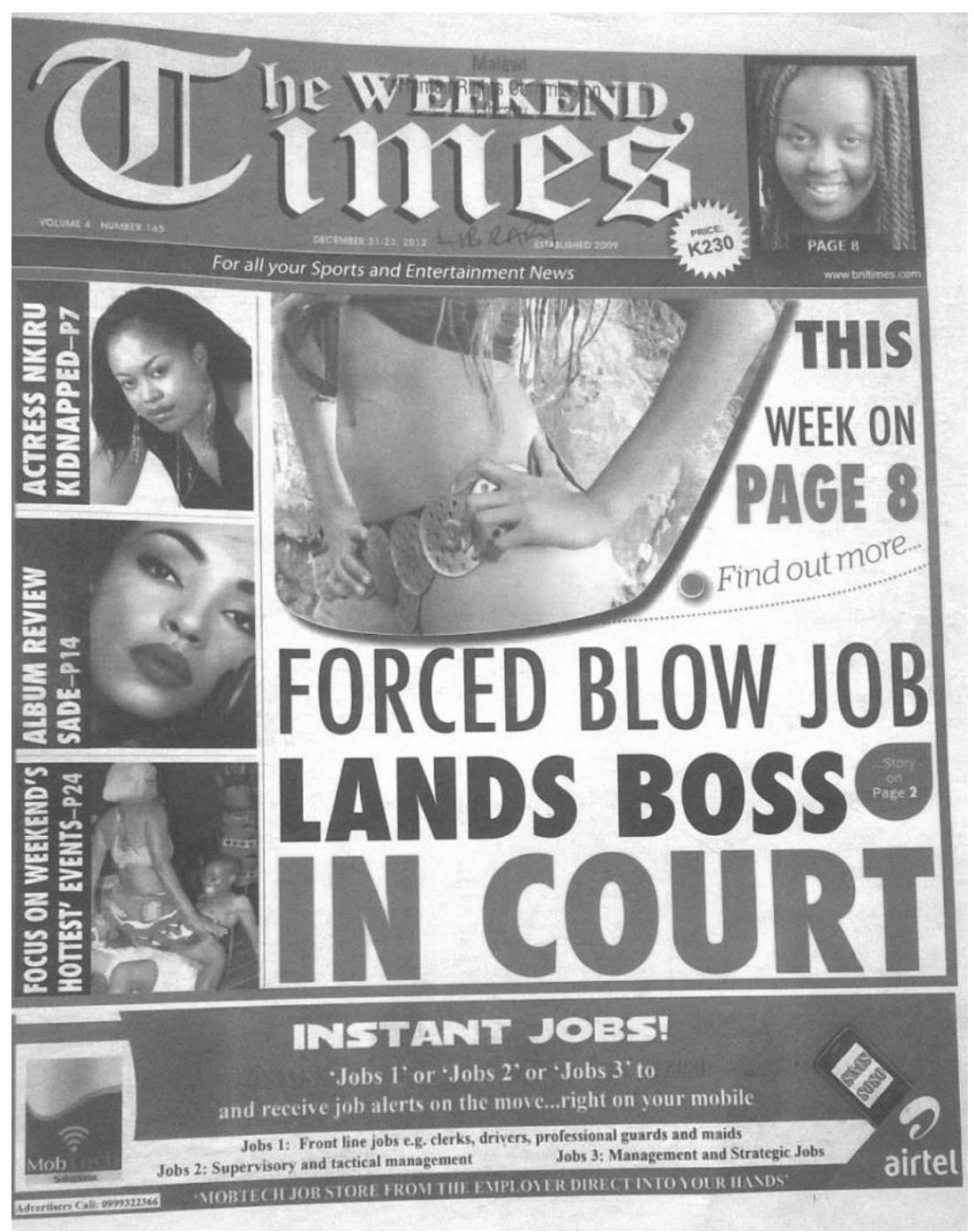

Note: Editions of The Weekend Times from April 19-21, 2013 and December 21-23, 2012. 
Figure 8 . The probability of stated rejection of men's violence against women increases with the number of anti-violence newspaper articles published in the 30 days prior to their personal survey interview dates.

\section{Women}

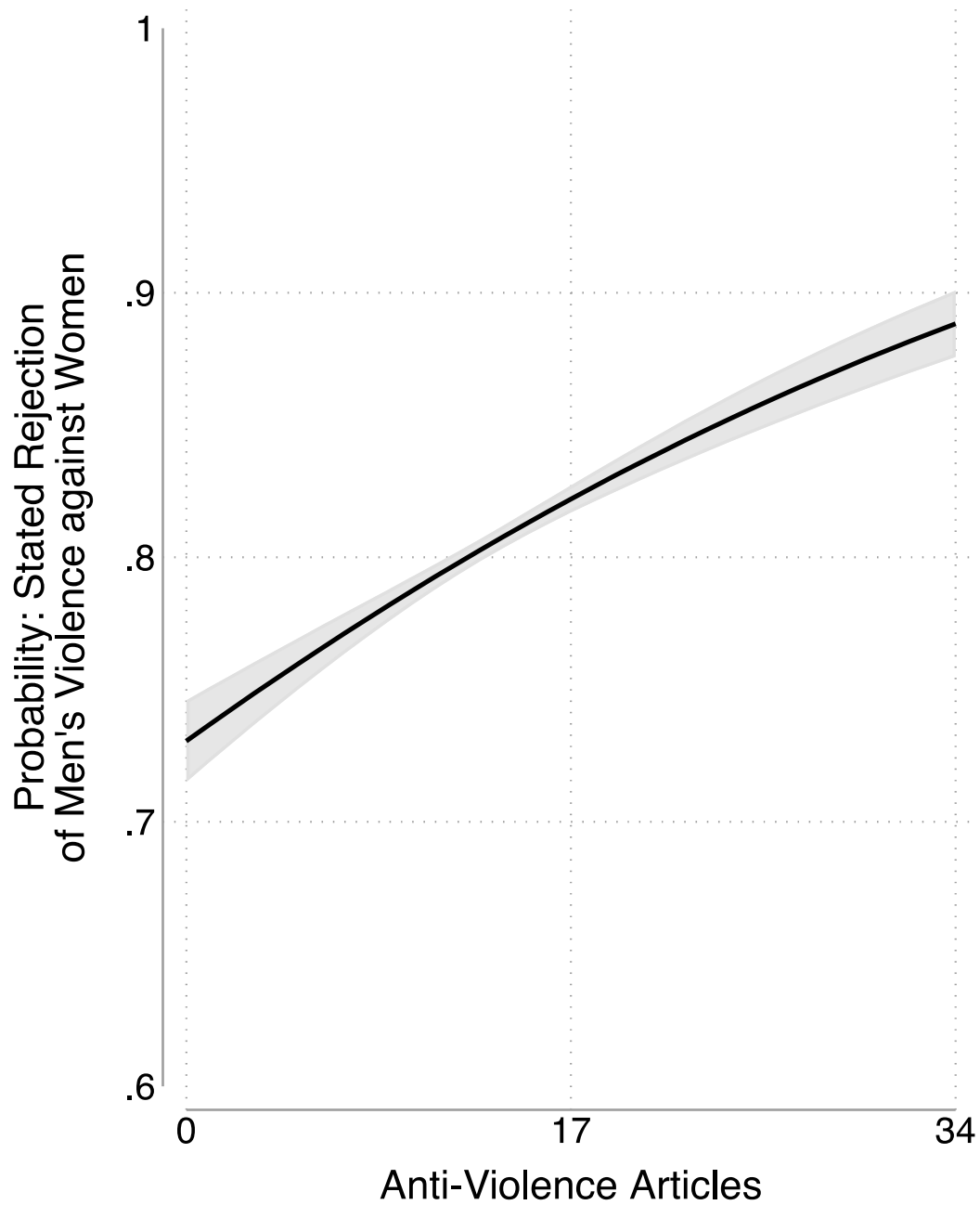

Men

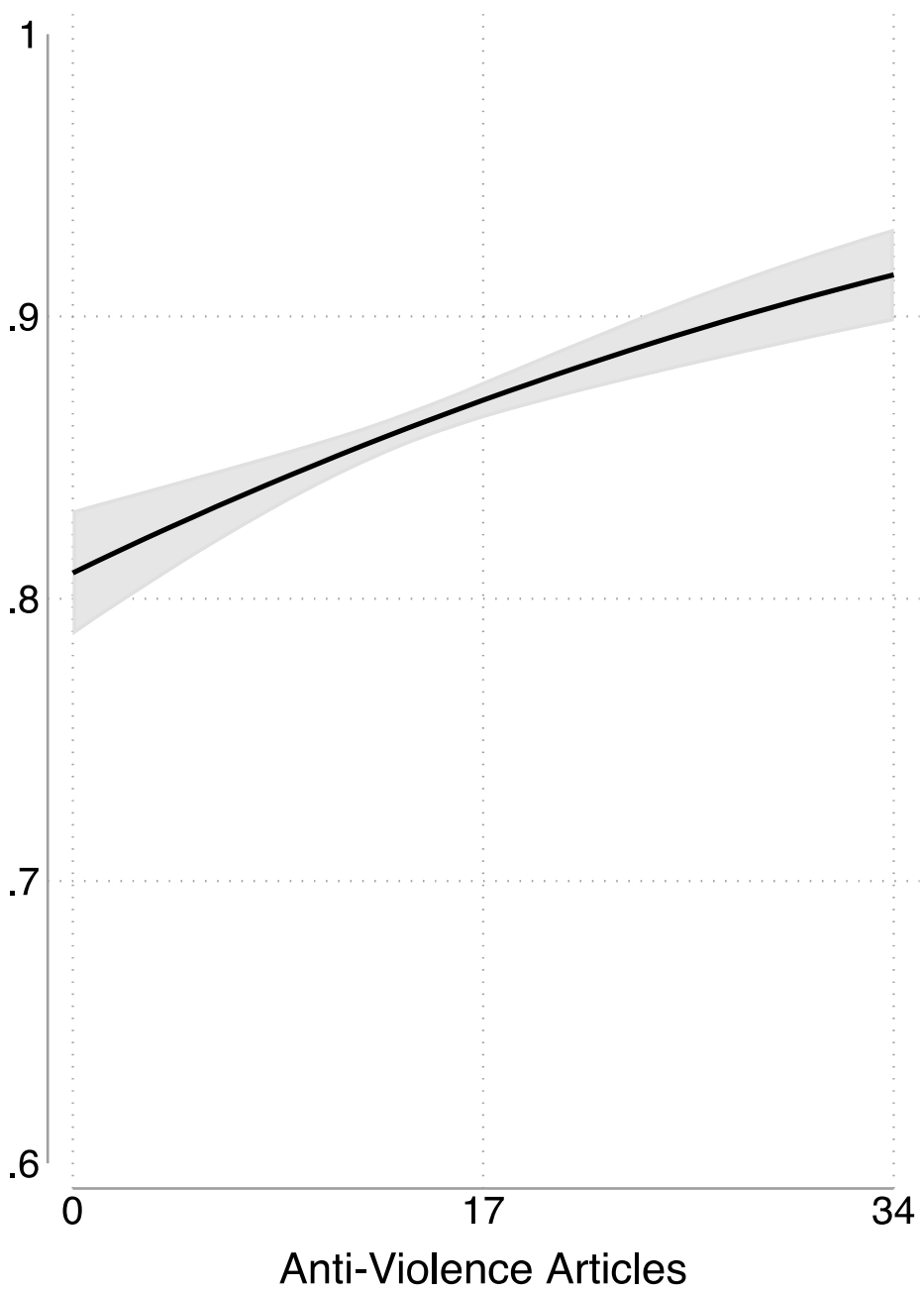

Note: Results obtained from Table 2, Model 1. Shading indicates 95 percent confidence intervals. 
Figure 9. The probability of stated rejection of men's violence against women is highest among those that listen to the radio weekly and that have heard all four anti-violence radio programs.

Women

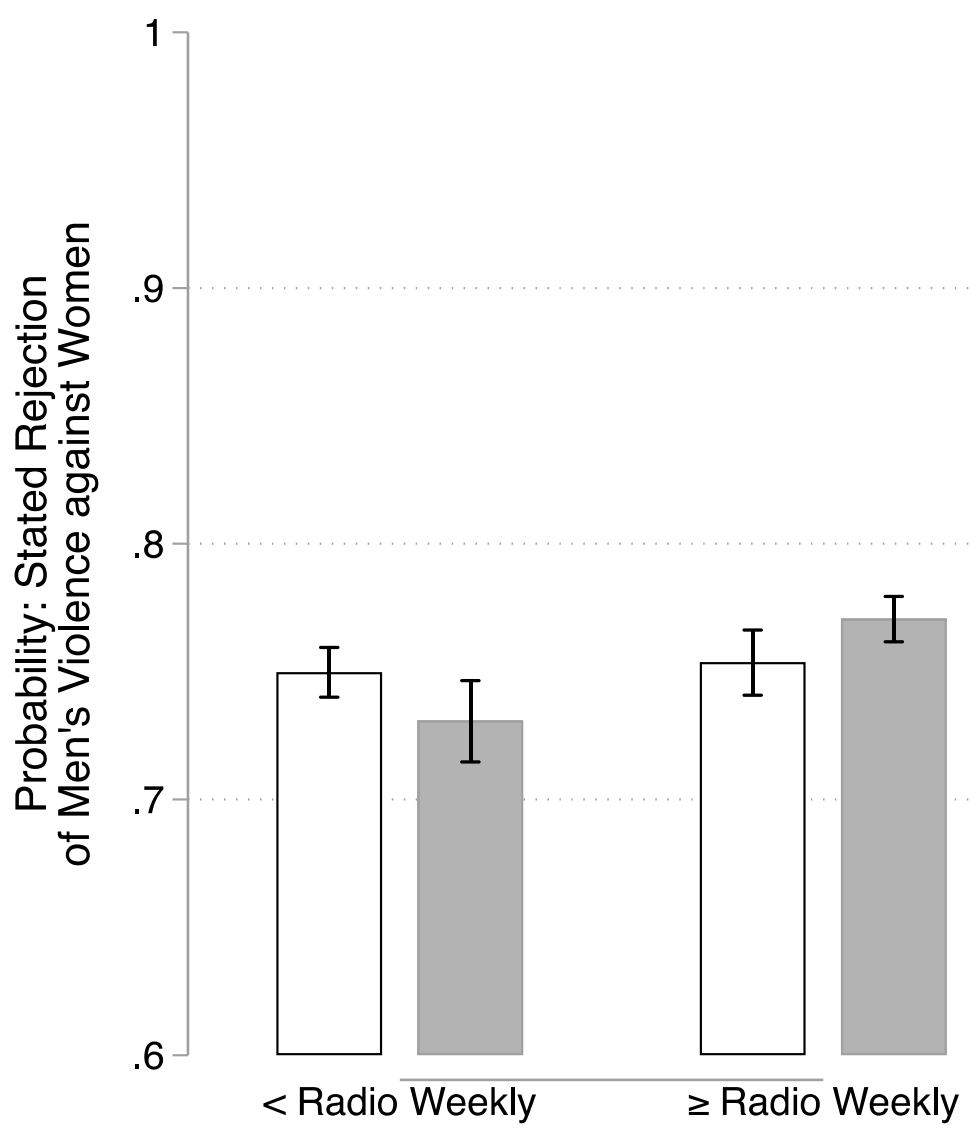

Men

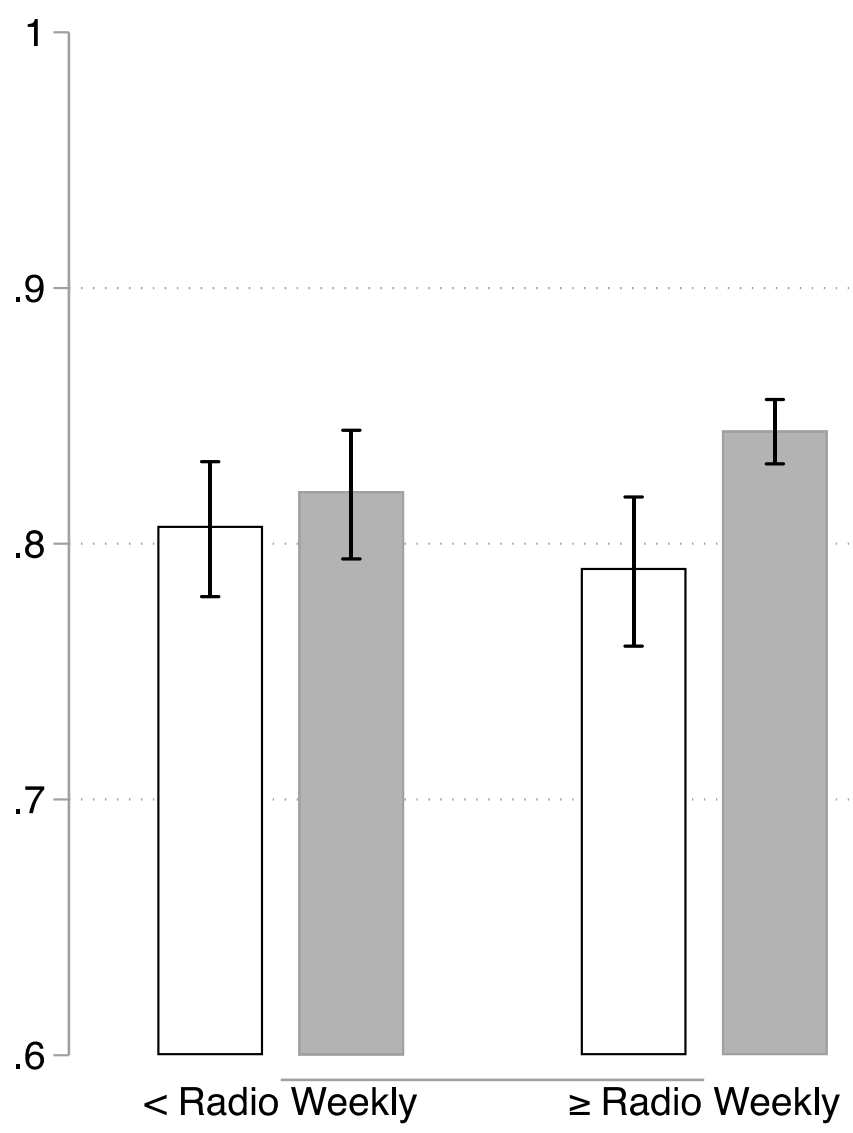

Anti-Violence Radio Programs:

None

Note: Results obtained from an altered replication of Table 2, Model 2 that includes an interaction between the number of antiviolence radio programs heard and at least weekly radio use. Shading indicates 95 percent confidence intervals. 
Figure 10. The average marginal effects of weekly television use on stated rejection of men's violence against women were negative in 2010 and positive in 2013-2014.
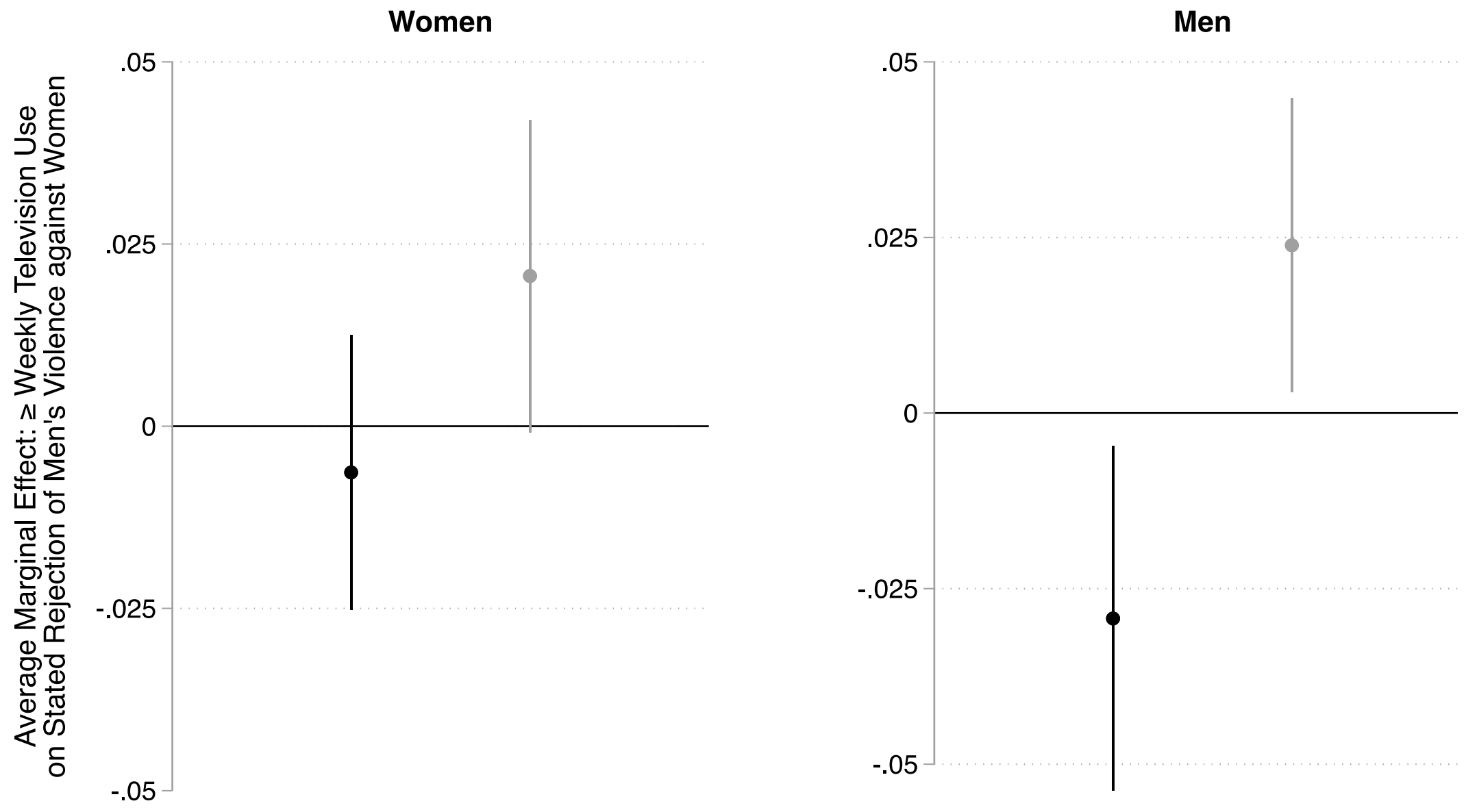

\section{Survey Year:}

2010

2013-2014

Note: Results obtained from altered replications of Table 2, Model 3 that use only the 2010 and 2013-14 surveys, respectively. Vertical lines indicate 95 percent confidence intervals. 